\title{
"Por la agudeza de los equívocos". Nuevas perspectivas sobre las relaciones entre música y poesía en la España del siglo XVII
}

\author{
"For the Wit of the Double Entendres". \\ New Perspectives on the Relationship between \\ Music and Poetry in Seventeenth-century Spain
}

El presente artículo pretende contribuir al conocimiento sobre las relaciones entre música y poesía en la España del siglo XVII, mediante el estudio de un caso en concreto. Se trata de una pieza anónima conservada en el Libro de tonos humanos (1656) y cuyo texto pertenece a Antonio Hurtado de Mendoza. Si bien esta obra ha sido analizada en estudios previos, este trabajo pone en evidencia aspectos desconocidos de la misma, como el sentido figurado que esconde, su abundante uso del equívoco y el modo en el que todo esto se manifiesta en la música. Además, demuestra que estos procedimientos resultan extrapolables a otras obras de dicho cancionero, por lo que su identificación puede ser útil para futuros trabajos sobre el tono y el villancico. Finalmente, se plantean hipótesis sobre la posibilidad de que el texto incluya referencias veladas a situaciones y personajes concretos del Madrid de los Austrias.

Palabras clave: siglo XVII, tonos humanos, Corte de Madrid, equívocos, música y significado, erotismo.

This article aims to contribute to knowledge about the relationship between music and poetry in seventeenth-century Spain, by studying a specific case. The work in question is an anonymous piece preserved in the Libro de tonos humanos (1656) and whose text was written by Antonio Hurtado de Mendoza. Although this work has been analysed in previous studies, this article highlights some of its unknown aspects, such as the figurative meaning it conceals, its extensive use of double entendre and the way in which this is manifest in music. It also demonstrates that these procedures can be extrapolated to other works from this song-

* Una versión preliminar de este trabajo fue incluida en la conferencia "Historia y etnografía / Musicología histórica y etnomusicología”, que ofrecí en el CENIDIM de México en el marco de la Cátedra Jesús Romero (7-11-2018). Agradezco a Josefina Guilleminot su lectura y comentarios al texto, así como a los dos revisores anónimos sus sugerencias. 
book, making their identification useful for future studies about the tono and the villancico. Finally, various hypotheses are formulated about the possibility that there are veiled references in the text to specific situations and people from Hapsburg Madrid.

Keywords: 17th century, tonos humanos, Court of Madrid, double entendres, music and meaning, eroticism.

Nuevas de la Corte de 28 de enero de 1662

En 22 y 23 de este celebró el Supremo Consejo de Aragón, en el Colegio Imperial de la Compañía de Jesús, la fiesta de la Inmaculada Concepción de Nuestra Señora con ocasión de la nueva Bula de nuestro sumo Pontífice Alejandro VII, en que declara el intento de la Santa Iglesia Romana acerca del objeto de la dicha fiesta. Hubo primeras vísperas y, el día siguiente, misa solemne y completas, y a todas tres funciones asistió el Consejo pleno con la grandeza y autoridad que suele. El altar estuvo majestuoso; el concurso, lucido y grande; los fuegos artificiales, muy ingeniosos; las luminarias y faroles, muchos. Dio cumplimiento a la fiesta el sermón que predicó el P. Pedro Francisco Esquex, hijo de Zaragoza y predicador de Su Majestad, con la agudeza, piedad y aplauso muy proprios y debidos a su gran talento. La música fue la de la Capilla Real, hoy aumentada con nuevas y muy agradables voces. Cantaron dos Romances que merecieron extraordinarias aclamaciones por la agudeza de los equívocos. Los traslados van con esta relación, y para más fácil inteligencia de los conceptos se supone que el embajador extraordinario que tiene $\mathrm{Su}$ Majestad en Roma por agente y solicitador de este piadoso misterio, y que ha conseguido de su Santidad la declaración que se contiene en la Bula, es el excelentísimo Señor D. Luis Crespi deVillaora [sic, porValldaura], obispo de la Ciudad de Plasencia y hermano del Ilustrísimo SeñorVice Canciller del Supremo Consejo de Aragón. Esto supuesto, se entenderán mejor las dicciones de ambos romances. En el mismo Colegio Imperial celebrará la villa la misma fiesta con otavario, y baste esta noticia para entender que será con la mayor obstentación que se habrá visto en caso semejante ${ }^{1}$.

El texto citado se halla en un manuscrito de mediados del siglo XVII que contiene una serie de "avisos" relativos a la corte de Madrid. Este, en particular, describe las ceremonias que tuvieron lugar en el Colegio Imperial de la villa a comienzos de 1662, para celebrar la bula papal recientemente promulgada que reafirmaba el culto a la Inmaculada Concepción de María. Lo más llamativo para el presente trabajo es la referencia a los dos "romances" que cantó la Real Capilla. Muy probablemente, el término alude a la forma poética consistente en una serie de cuartetas octosilábicas con rima asonante en los versos pares. El género musical, sin embargo, resulta menos claro. Dado el motivo religioso de la fiesta, es probable que se trate de villancicos, esto es, de piezas sacras en lengua vernácula. De hecho,

${ }^{1}$ Madrid, Biblioteca Nacional de España, Mss. 2396, Avisos del siglo XVII, f. 229. Las cursivas son mías. En la transcripción de los textos de la época -incluso cuando son citados por otros autores- he normalizado la puntuación y la ortografía, excepto cuando esta tiene implicaciones fonéticas. 
el romance era, junto con la letrilla, la forma poética más empleada para su composición ${ }^{2}$. Sin embargo, también es posible que el documento aluda a tonos humanos, es decir, composiciones musicales en lengua vernácula, pero de carácter profano ${ }^{3}$. Después de todo, las fiestas religiosas solían incluir, además de villancicos, "romances burlescos" con toda clase de referencias a quienes participaban en la celebración ${ }^{4}$.

Sea como fuere, el hecho de que los romances fuesen aclamados "por la agudeza de los equívocos" hace pensar que, pese a la escasa atención que les ha dedicado la musicología española e hispanoamericana, estos eran relevantes para la música vernácula del período. En su célebre tratado de retórica, reeditado y ampliado en 1648, Baltasar Gracián define al equívoco como "una palabra de dos cortes y un significar a dos luces", cuyo artificio consiste "en usar de alguna palabra que tenga dos significaciones; de modo que deje en duda lo que se quiso decir". Según este autor, el equívoco se usa a veces "para exprimir mayor misterio y profundidad", y cuando se relaciona con "las circunstancias o adjuntos del sujeto, participa de mayor artificio". Aunque su sentido pueda explicarse en el propio texto, se evita hacerlo cuando la intención "es maliciosa y satírica", o "atrevida y peligrosa". En otras ocasiones, el equívoco se explica mediante "otra palabra contraria, y entonces el concepto no se funda por correspondencia de la una significación con la otra, sino por oposición...”. Finalmente, Gracián afirma que esta figura literaria puede mezclarse "con todas las demás especies

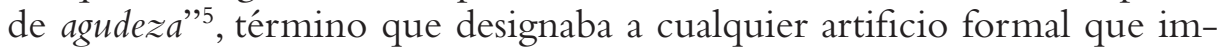
plicara para la inteligencia "un ejercicio gimnástico de desciframiento"

Luego de señalar la presencia de equívocos en los romances cantados, el aviso de 1662 proporciona las claves para comprenderlos. Estas se relacionan con el parentesco que existía entre el obispo de Plasencia y

2 Álvaro Torrente: "El villancico religioso", Historia de la música en España e Hispanoamérica. 3. La música en el siglo XVII, Álvaro Torrente (ed.), Madrid, Fondo de Cultura Económica de España, 2016, p. 502; Gerardo Arriaga: José Marín (ca. 1619-1699). Tonos y villancicos. Estudio y edición, Madrid, ICCMU, 2008, pp. 58-62.

${ }^{3}$ Para una visión de conjunto sobre el género véase, entre otros, Miguel Querol: "El romance polifónico en el siglo XVII", Anuario Musical, 10, 1955, pp. 111-120; Luis Robledo: Juan Blas de Castro (ca. 15611631). Vida y obra musical, Zaragoza, Institución Fernando el Católico, 1989; Mariano Lambea, Lola Josa (eds.): Libro de tonos humanos (1655-1656). Volumen I, Barcelona, CSIC, Institución Milà i Fontanals, 2000; Alejandro Vera: Música vocal profana en el Madrid de Felipe IV: el "Libro de tonos humanos" (1656), Lleida, Institut d'Estudis Ilerdencs, 2002.

${ }^{4}$ Además, era frecuente que los compositores escribieran sus villancicos a partir de algún tono humano preexistente. Á. Torrente: "El villancico religioso...", pp. 441-446, 490.

${ }^{5}$ Lorenzo [= Baltasar] Gracián: Agudeza y arte de ingenio, Huesca, Iván Nogués, 1648, pp. 227-235. Las cursivas son mías. Para una definición contemporánea del equívoco o dilogía véase Helena Beristáin: Diccionario de retórica y poética, México D. F., Editorial Porrúa, 1995, pp. 151-152.

${ }^{6}$ Siguiendo a Mercedes Blanco: "El mecanismo de la ocultación. Análisis de un ejemplo de agudeza", Criticón, 43, 1988, p. 35. 
embajador de España en Roma, quien había conseguido la gracia papal, y un alto miembro del Supremo Consejo de Aragón. En otras palabras, los equívocos contenían referencias veladas o indirectas a lo que Gracián llamaría "las circunstancias o adjuntos del sujeto". Desafortunadamente, resulta imposible ir más allá en este punto, por no haberse conservado copia de los romances.

Pese a haber sido publicado a finales del siglo XIX por Paz y Meliá7, el texto citado no ha sido objeto de atención en ningún estudio musicológico. Sin embargo, proporciona claves importantes para comprender mejor los vínculos entre música y poesía en la España del siglo XVII. Para comprobarlo, el presente trabajo estudia un tono humano de gran interés poético y musical que ya ha sido objeto de atención en estudios recientes, pero, aun así, se encuentra necesitado de nuevas aproximaciones que contribuyan a entenderlo más íntegramente. Una vez presentado el estado de la cuestión, se analiza la pieza señalada para demostrar ${ }^{8}$ que, además del significado literal ya explicado por otros especialistas, esconde un sentido figurado que solo se hace evidente cuando se toma consciencia de los equívocos que contiene.

La decisión de concentrar la atención en una pieza específica antes que en un corpus amplio de casos podría despertar dudas acerca del real alcance de este trabajo, pero se sustenta en la premisa de que un análisis intensivo, aun cuando se haga sobre un caso o corpus acotado, puede resultar tan provechoso como un análisis a gran escala ${ }^{9}$. Además, el estudio pone en evidencia que los procedimientos identificados estaban presentes en otros tonos del siglo XVII, por lo que su conocimiento amplía nuestra comprensión no solo de una obra en particular, sino de la música vernácula española en general. Finalmente, y dado que la pieza en cuestión procede a todas luces del entorno cortesano, se formulan hipótesis sobre la posibilidad de que refiera a situaciones y personajes concretos del Madrid de los Austrias.

\footnotetext{
${ }^{7}$ Antonio Paz y Meliá (ed.): Avisos de D. Jerónimo de Barrionuevo (1654-1658) y apéndice anónimo (16601664). Tomo IV, Madrid, Imprenta y Fundición de M. Tello, 1893, pp. 417-418.

${ }^{8}$ El término debe entenderse aquí en un sentido relativo, dada la incertidumbre propia de cualquier investigación histórica. Lo que sí intento ofrecer es un relato verosímil y coherente con la evidencia reunida. Leo Treitler: Music and the Historical Imagination, Cambridge, Massachusetts, Londres, Harvard University Press, 1989, especialmente pp. 43-44, 118. A esta dificultad se añade que "la aplicación de la retórica a la música no es una ciencia dura, ni tampoco una doctrina histórica única y consistente...". Bernardo Illari: Polychoral Culture: Cathedral Music in La Plata (Bolivia), 1680-1730, tesis doctoral, University of Chicago, 2001, p. 171.

${ }^{9}$ El postulado proviene de la microhistoria, cuyos fundamentos fueron esbozados en la década de los setenta por Carlo Ginzburg: "Indicios. Raíces de un paradigma de inferencias indiciales", Mitos, emblemas e indicios, Barcelona, Gedisa, 1994, pp. 138-175. Puede verse una síntesis sobre dicha corriente en José D’Assunção Barros: El campo de la historia: especialidades y abordajes, Santiago de Chile, Universidad Católica Silva Henríquez, 2008, pp. 150-157.
} 


\section{Estado de la cuestión}

La importancia de los equívocos en el villancico religioso ya ha sido advertida en estudios anteriores, aunque mayormente en el campo de la filología. Por ejemplo, en un trabajo reciente, Robin Ann Rice demuestra que los villancicos a San Pedro que sor Juana Inés de la Cruz escribió en 1677 hacen gala de un sofisticado uso de equívocos, que combina una extrema altura intelectual con analogías y burlas comprensibles para todos ${ }^{10}$.

En el campo musicológico, en cambio, escasean los trabajos sobre el tema, pese a que la importancia del conceptismo y de la polisemia dentro del género sí ha sido advertida por la musicología ${ }^{11}$. Sin embargo, existe una excepción de especial relevancia para este trabajo: el estudio de Janet Hathaway sobre un proceso que la Inquisición de Madrid abrió en 1663, con motivo de dos villancicos que habían sido ejecutados poco tiempo antes en varias instituciones monásticas de la villa ${ }^{12}$. Uno de ellos, "Madrugaron tres Marías" -escrito por el compositor Tomás Miciezes padre y el poeta Tomás de Oña-, fue interpretado el Sábado Santo de dicho año en el Convento de La Victoria. En una primera lectura, su texto describe la visita de las tres Marías a la tumba de Jesús y su encuentro con el ángel que les anuncia la resurrección. Sin embargo, está repleto de dobles sentidos eróticos, que presentan a las mujeres como personas proclives a realizar actividades poco decorosas a escondidas de sus hombres ("que las mujeres madrugan / siempre por salir de casa") y a apartarse deliberadamente de las convenciones sociales ("salieron por ir de prisa / las tres Marías, sin Marta") ${ }^{13}$. Peor aún, en las cercanías del Convento de La Victoria se hallaba la Iglesia de Jesús, a la que solían acudir célebres actrices de la época, como María Calderón, María de Córdoba y María Riquelme. Por esta razón, la misa a la que asistían en dicha iglesia era conocida popularmente como "la misa de las Marías". Así, quienes presenciaron la ejecución del villancico debieron establecer asociaciones lejanas a los sentimientos de devoción y recogimiento que la celebración ameritaba -Calderón era la amante de Felipe IV y tanto los actores como las actrices tenían fama de llevar una vida disipada $-{ }^{14}$.

\footnotetext{
${ }^{10}$ Robin Ann Rice: “'Oigan un silogismo señores': erudición y burla en los villancicos de Sor Juana para celebrar San Pedro Apóstol en 1677", Barroco de ambos mundos. Miradas desde Puebla, Ignacio Arellano, Robin Ann Rice (eds.), Nueva York, IDEA, 2019, pp. 263-284.

${ }^{11}$ Á. Torrente: "El villancico religioso...", pp. 446-447.

12 Janet Hathaway: "Laughter and Scandal: An Inquisition Censure in Late Hapsburg Madrid", Acta Musicologica, 75, 2, 2003, pp. 243-268; - Cloister, Court and City: Musical Activity of the Monasterio de las Descalzas Reales (Madrid), ca. 1620-1700, tesis doctoral, New York University, 2005, pp. 235-264.

${ }^{13}$ Como Hathaway señala, en el relato bíblico, Marta representa la convención y la tradición. J. Hathaway: "Laughter and Scandal...", pp. 251.

${ }^{14}$ Ibid., pp. 249-255.
} 
Hathaway cita otro documento inquisitorial, esta vez sin lugar ni fecha, pero que parece cercano a 1663, y alude a los géneros músico-poéticos en boga en el Madrid de la época. El texto comparte con el proceso anterior la preocupación por la introducción de elementos profanos en el villancico, pues afirma que en las festividades religiosas se cantan "unas letras con palabras equívocas que tienen dos sentidos, y el más usual y común unas veces es vano y otras profano..."15.

Así, pues, el trabajo de Hathaway confirma la importancia que el equívoco tenía para el villancico. Sin embargo, el hecho de no haberse conservado partituras para las piezas que ella estudia impide saber si su empleo literario iba aparejado o no de procedimientos musicales específicos.

Esto último es probable si se considera la música vocal profana del mismo período. Los estudios sobre el tono humano han demostrado que este se caracteriza por una estrecha relación entre el texto y la música. Si bien esto ya fue advertido por los primeros estudiosos del género ${ }^{16}$, trabajos más recientes y detallados han puesto en evidencia que dicha relación operaba a distintos niveles.

Uno de estos era el que vinculaba la estructura poética y la secuencia sonora. Según Pelinski, en el Cancionero de Sablonara (1626) el límite de cada verso suele demarcarse por medio de una cadencia y los puntos de asonancia coinciden, generalmente, con un mismo sonido o tríada compuesta. Así mismo, el acento principal del verso - con frecuencia situado en la penúltima sílaba- coincide con una cadencia que se "estira" rítmicamente, para dar lugar a un retardo.Y cuando el verso comienza con una anacrusa la música tiende a desviarse de las notas principales del "tono", pero solo de manera transitoria. En otras palabras, el compositor se esfuerza para que exista una correspondencia sonora entre el texto y la música ${ }^{17}$.

Esta correspondencia afectaba igualmente al ritmo. González Valle sugiere que la complejidad rítmica y métrica de los tonos y villancicos del siglo XVII se relaciona con la variedad acentual de la poesía española del mismo período, así como con una tendencia de los poetas y músicos a alejarse del tipo de declamación propio del siglo anterior, influido por la

${ }^{15}$ Ibid., pp. 256-257. De la misma forma, aunque en una época posterior (1726), el padre Feijoo afirma que "Toda la gracia de las cantadas que hoy suenan en las iglesias, consiste en equívocos bajos, metáforas triviales, retruécanos pueriles..." -citado, entre otros, por Narciso Alonso Cortés: "Pliegos de villancicos", separata de Revista Bibliográfica, 4, 3, 1943, p. 2.

${ }^{16}$ Pedrell, por ejemplo, expresaba en 1897 su admiración hacia los tonos del compositor Carlos Patiño, maestro de la Real Capilla, por "el expresivismo de sus composiciones dimanado del concepto poético del texto, a veces transformado idealmente con objeto de obtener mayores bellezas". Felipe Pedrell: Teatro lírico español anterior al siglo XIX, La Coruña, Canuto Berea y Compañía, 1897, vol. 3, p. XXIX.

${ }_{17}^{17}$ Ramón Pelinski: Die Weltliche Vokalmusik Spaniens am Anfang des 17. Jahrhunderts, Tutzing, Hans Schneider, 1971, pp. 146-149. 
prosa latina ${ }^{18}$. Desde luego, esta posible explicación no excluye que tal variedad se relacione también con la influencia de la danza, como han propuesto otros autores ${ }^{19}$.

La textura, por su parte, estaba condicionada a la inteligibilidad del texto. Tanto en el Cancionero de Sablonara como en el Libro de tonos humanos (1656) -las colecciones de tonos polifónicos que han sido más estudiadas- las estrofas del romance se escriben predominantemente en una textura homofónica y los pasajes contrapuntísticos o imitativos se reservan para el último verso de la cuarteta, momento en el que su significado ya ha sido comprendido por el oyente. No es casualidad que el estribillo presente una mayor elaboración musical, dado que su texto suele estar escrito en torno a una sola idea poética, que con frecuencia deriva del romance ${ }^{20}$.

Pero el nivel más estudiado es el semántico y retórico. Si bien los tratadistas españoles del siglo XVII no detallan los recursos específicos que se utilizaban para expresar musicalmente el sentido del texto, como sí hacen los de otras latitudes ${ }^{21}$, todos ellos consideran dicho aspecto como un objetivo prioritario para el compositor y coinciden en aceptar toda clase de "licencias" si contribuyen a alcanzarlo22.

Este interés es patente en los tonos conservados. En su versión más simple, el compositor introduce pasajes que de algún modo imitan o alegorizan el texto. Se trata de partículas musicales que la literatura contemporánea

\footnotetext{
${ }^{18}$ José Vicente González Valle: "Relación música / texto en la composición musical en castellano del s. XVII. Nueva estructura rítmica de la música española", Anuario Musical, 47, 1992, pp. 103-132; —: "Relación entre el verso castellano y la técnica de composición musical en los villancicos de Fr. Manuel Correa (s. XVII)", Anuario Musical, 51, 1996, pp. 39-69. Un estudio detallado sobre la correspondencia entre tipos de versos y esquemas rítmicos en los tonos de José Marín puede verse en G. Arriaga: José Marín..., pp. 62 72. La importancia de este aspecto es señalada por Illari para los villancicos conservados en Sucre. Según el autor, en estas obras la relación entre música y texto se da a nivel de la pronuntiatio, conforme a la retórica ciceroniana, pues, la mayor parte del tiempo, la música no dice nada sobre el significado del texto, pero captura en cambio su ritmo y métrica; es decir, su forma de hablar (utterance), más que su contenido. Véase B. Illari: Polychoral Culture..., pp. 171-172.

${ }^{19}$ Judith Etzion (ed.): El Cancionero de la Sablonara, Londres, Tamesis Books, 1996, pp. LII-LIV; R. Pelinski: Die Weltliche Vokalmusik..., pp. 177-178.

${ }^{20}$ M. Querol: "El romance polifónico...", pp. 112-113; L. Robledo: Juan Blas de Castro..., pp. 78-86; J. Etzion: El Cancionero de la Sablonara, pp. XL, L-LIV; A. Vera: Música vocal profana..., pp. 165-167.

${ }^{21}$ Burmeister y otros teóricos germanos elaboraron extensos listados de figuras retórico-musicales que servían al propósito señalado. Véase Rubén López Cano: Música y retórica en el Barroco, Barcelona, Amalgama Edicions, 2012. Ezquerro propone que esta diferencia se debió al carácter gremial y consiguiente halo de hermetismo que caracterizaba a la enseñanza de la música en España. Antonio Ezquerro: La música vocal en Aragón en el segundo tercio del siglo XVII, tesis doctoral, edición en microficha, Bellaterra, Publicacions de la Universitat Autònoma de Barcelona, 1998, vol. 2, pp. 23-25.

22 A. Ezquerro: La música vocal..., vol. 2, pp. 45-49, 61-67, 77-78; A. Vera: Música vocal profana..., p. 171; Álvaro Torrente: "Música de plata en un siglo de oro", Historia de la música en España e Hispanoamérica. 3. La música en el siglo XVII, Álvaro Torrente (ed.), Madrid, Fondo de Cultura Económica de España, 2016, p. 75.
} 
anglosajona suele designar como word painting y que en la tratadística barroca se entendían como figuras del tipo hipotiposis ${ }^{23}$. Por ejemplo, el tono "En invierno nacen las flores", escrito por Bernardo de Peralta y conservado en Romances y letras a tres voces (ca.1610), describe con motivos descendentes el verbo "bajar" 24 . Unos años más tarde, el Cancionero de Sablonara exhibe este mismo tipo de procedimiento en diversas obras, como el tono "En este invierno frío", atribuido al Maestro Capitán, en el que un ritmo punteado describe el movimiento inquieto del viento y de las nubes ${ }^{25}$.

Más subjetiva y compleja resulta la expresión de las emociones o "afectos". La disonancia constituye el recurso predominante para expresar afectos negativos como la tristeza y el dolor. En los cancioneros, suele emplearse con este fin lo que hoy categorizaríamos como una séptima de dominante en primera inversión - para la época, esta pertenecía a la familia de las "posturas" de "quinta falsa" o disminuida ${ }^{26}$. Sin embargo, veremos que el abanico de posibilidades era aún más variado.

Diversos estudios afirman que las disonancias más llamativas suelen aparecer en pasajes del texto que hacen uso de oxímoros, es decir, sucesiones de dos palabras o frases que desde un punto de vista literal parecen excluirse lógicamente. Sin embargo, la contradicción es solo aparente porque, de manera figurada, la sucesión de ambas ideas da lugar a un sentido coherente ${ }^{27}$. En Romances y letras a tres voces, el tono "Con el pecho en la boca", de Juan de la Peña, presenta una tríada con séptima, sin preparación, en el verso "se quedó dormido el bien de mi mal" 28 . Así mismo, en el tono "Con rigores premia Filis", de fray Bernardo Murillo, conservado en el Libro de tonos humanos, una séptima de dominante se prolonga más tiempo del habitual mientras el texto exclama "Dándome muerte, Filis me da vida" (ejemplo 1$)^{29}$. López Cano, por su parte, afirma que en los tonos de José Marín el oxímoron y la paradoja dan lugar a partículas musicales poco ortodoxas, como "Relaciones dominante-tónica especiales" 30 . La abundancia de estos pasajes en el

\footnotetext{
${ }^{23}$ Rubén López Cano: De la retórica a la ciencia cognitiva. Un estudio intersemiótico de los tonos humanos de José Marín (ca. 1618-1699), tesis doctoral, Universidad de Valladolid, 2004, pp. 161-162.

${ }^{24}$ Juan Jorquera: Presencia de la música en la Compañía de Jesús de Madrid durante la primera mitad del siglo XVII, tesis doctoral, Universidad Autónoma de Madrid, 2016, p. 477.

${ }^{25}$ R. Pelinski: Die Weltliche Vokalmusik..., pp. 95-96.

${ }^{26}$ Ibid., p. 137; L. Robledo: Juan Blas de Castro..., pp. 100-101; J. Etzion: El Cancionero de la Sablonara, p. LVII; M. Lambea, L. Josa: Libro de tonos humanos (1655-1656). Volumen III, Madrid, CSIC Institución Milà y Fontanals, 2005, p. 31, en este caso combinado con cromatismos.

${ }^{27}$ H. Beristáin: Diccionario..., pp. 373-374.

${ }^{28}$ J. Jorquera: Presencia de la música..., p. 485.

${ }^{29}$ A. Vera: Música vocal profana..., p. 173. Como se ve en dicho ejemplo, el verso presenta variantes en el tiple 1 y el tenor.

${ }^{30}$ R. López Cano: De la retórica a la ciencia cognitiva..., pp. 763, 775, 875, 942.
} 
repertorio del siglo XVII ha sido atribuida al gusto general de la estética barroca por los juegos de opuestos y a la capacidad del oxímoron para crear un efecto de misterio y profundidad ${ }^{31}$.

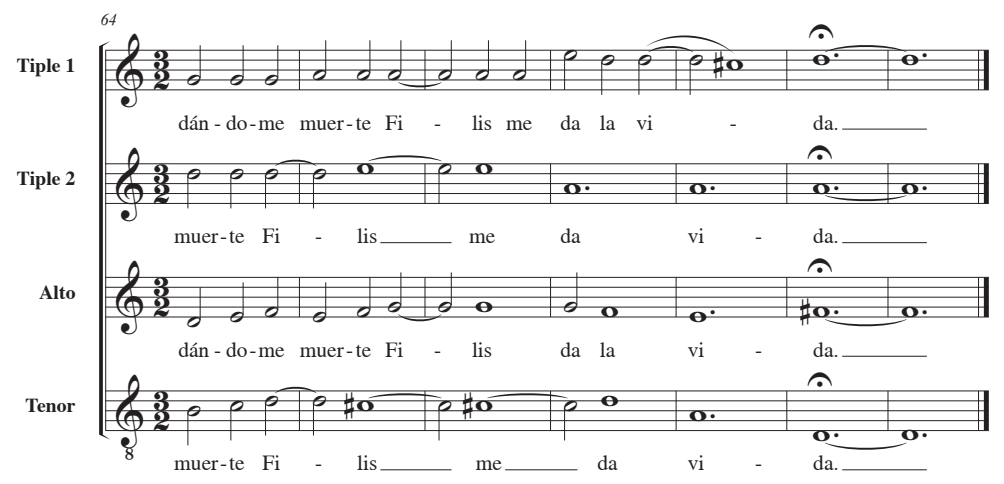

Ejemplo 1. Final del tono "Con rigores premia Filis", de fray Bernardo Murillo

Así como los compositores se sirven de la armonía para expresar afectos de uno u otro tipo, la melodía también puede desempeñar esta función. Por ejemplo, un tono a solo titulado "Llorando noches y días", probablemente interpretado en la comedia La vida de San Alejo, de Agustín Moreto (1657), hace uso del motivo del lamento para expresar el dolor de la protagonista (Sabina). Dicho motivo solía consistir en una sucesión de cuatro o cinco notas descendentes que transcurrían en valores largos y daban lugar a retardos. Fue empleado con frecuencia en el teatro musical de España y el resto de Europa (la ópera incluida) ${ }^{32}$, pero también lo hallamos en tonos no teatrales, como los del Libro de tonos humanos o los de José Marín ${ }^{33}$.

Otra forma de vincular música y texto consiste en aprovechar la relativa indeterminación semántica de la primera para reforzar el aura de misterio que rodea algunos mensajes o enunciados. Así ocurre, por ejemplo, en el tercer acto de $\mathrm{El} \mathrm{ca-}$ ballero de Olmedo, de Lope deVega, cuando la canción "Que de noche le mataron / al caballero..." anticipa crípticamente el funesto destino del protagonista ${ }^{34}$.

\footnotetext{
${ }^{31}$ M. Lambea, L. Josa: Libro de tonos humanos (1655-1656). Volumen I, p. 82; A. Vera: Música vocal profana..., p. 173; R. López Cano: De la retórica a la ciencia cognitiva..., pp. 104, 802-803; H. Beristáin: Diccionario..., p. 374.

${ }^{32}$ Louise K. Stein: Songs of Mortals, Dialogues of the Gods. Music and Theater in Seventeenth-Century Spain, Oxford, Clarendon Press, 1993, pp. 53, 82-184; María Asunción Flórez: Música teatral en el Madrid de los Austrias durante el Siglo de Oro, Madrid, ICCMU, 2006, pp. 134 y ss., 153 y ss.

${ }^{33}$ A. Vera: Música vocal profana..., p. 172; R. López Cano: De la retórica a la ciencia cognitiva..., pp. 566571, 645-828.

${ }^{34}$ Véase más sobre este aspecto en L. K. Stein: Songs of Mortals..., pp. 23, 26-27, 140-143, 177, 228 , 265-267.
} 
Ahora bien, los gestos musicales que hemos descrito no solían despertar por sí solos un significado específico. La capacidad de la música para "mover los afectos" dependía en gran medida de los intérpretes, como prueba el hecho de que las críticas de los moralistas se refieran especialmente al acto de ejecución ${ }^{35}$. Además, los oyentes de la época compartían con el poeta y el compositor un mismo contexto cultural, lo que posibilitaba que pudieran comprender pasajes que hoy nos parecerían demasiado crípticos. Si bien no siempre es posible reconstruir dicho contexto, se ha demostrado que, al provenir muchos de los tonos conservados del entorno cortesano, algunas de las figuras o metáforas que contienen aluden a personajes y situaciones de la corte. Por ejemplo, el tono "Fuego baja de la cumbre", conservado en el Libro de tonos humanos y cuyo estribillo dice "Llega en buen hora, / bella alemana...", alude a Mariana de Austria, segunda esposa de Felipe IV, oculta bajo el nombre de Marcia. Por tanto, debió ser compuesto en 1649, cuando ambos contrajeron matrimonio ${ }^{36}$.

Concluyo esta sección con dos ideas generales que se desprenden de este estado de la cuestión. La primera es que, al no hallarse en la teoría española del siglo XVII una descripción detallada de los procedimientos utilizados para expresar musicalmente el sentido del texto, el musicólogo debe recurrir a la propia música y su contexto para intentar reconstruir el significado que las piezas estudiadas tenían para los oyentes de la época ${ }^{37}$. Desde luego, esto no implica prescindir de los testimonios teóricos cuando puedan resultar útiles para dicho intento.

La segunda puede sintetizarse así: en el caso del villancico, el equívoco ha sido estudiado, pero sin considerar sus posibles implicancias musicales; en el caso del tono humano, en cambio, se han estudiado bastante los procesos musicales de significación, pero el equívoco brilla por su ausencia. Por tanto, queda abierta la pregunta respecto a cómo afectaba esta figura retórica al discurso musical. Este es uno de los vacíos que el presente trabajo espera contribuir a llenar.

${ }^{35}$ Luis Antonio González Marín: "Recuperación o restauración del teatro musical español del siglo XVII", La ópera en España e Hispanoamérica, Emilio Casares, Álvaro Torrente (eds.), Madrid, ICCMU, 2001, vol. 1, pp. 67-69.

${ }^{36}$ M. Lambea, L. Josa: Libro de tonos humanos (1655-1656). Volumen I, p. 50.

${ }^{37}$ R. López Cano: De la retórica a la ciencia cognitiva..., pp. 17-18, quien describe este proceso como reconstrucción de un "escucha modelo". 


\section{El tono "Heridas en un rendido"}

El tono "Heridas en un rendido" se conserva en el Libro de tonos humanos, manuscrito compilado hacia 1656 que contiene 222 tonos polifónicos ${ }^{38}$. Como es sabido, este cancionero musical fue copiado en el Convento del Carmen de Madrid por el carmelita Diego Pizarro, cantor “capón”, por lo cual no es de extrañar que incluya numerosas obras de dos religiosos de la orden que vivieron en el convento hacia mediados del siglo XVII: fray Bernardo Murillo y el célebre compositor portugués fray Manuel Correa ${ }^{39}$. Este último, de hecho, fue maestro de capilla de la institución, como ha podido confirmarse recientemente ${ }^{40}$.

Al mismo tiempo, se ha demostrado que Pizarro realizó parte de la copia a partir de unos fascículos de papel pautado en los que otro copista ya había apuntado algunos tonos. El hecho de que la caligrafía de este último coincida con el manuscrito musical de Fortunas de Andrómeda y Perseo, comedia mitológica de Calderón de la Barca que fue representada en el Buen Retiro (1653), implica que debió tratarse de un copista de la corte. De modo que, sin perjuicio de su procedencia carmelitana, el Libro de tonos humanos debió copiarse en parte en la Corte de Madrid. Por esta razón, tampoco es de extrañar que incluya obras de compositores vinculados a la Real Capilla o la Cámara Real, como Mateo Romero "Capitán” y Carlos Patiño $^{41}$.

Esta vinculación con la corte es coherente con lo que sabemos de "Heridas en un rendido". Si bien Pizarro no indicó ni el nombre del compositor ni el del autor del texto, Judith Etzion identificó a este último hace ya tiempo ${ }^{42}$. Se trata de Antonio Hurtado de Mendoza (1586-1644), notable poeta y dramaturgo español que trabajó en Palacio a partir de 1621, cuando entró a servir como ayuda de guardarropa de Felipe IV. Ese mismo año fue promovido a ayuda de cámara y dos años después, al tiempo que ingresaba en la orden de Calatrava, fue

\footnotetext{
${ }^{38}$ Madrid, Biblioteca Nacional de España, M. 1262, ff. 8v-9. El lector dispone de una buena edición moderna en M. Lambea, L. Josa: Libro de tonos humanos (1655-1656). Volumen I, pp. 37-38 (texto), 110-115 (música). Aun así, ofrezco en el apéndice mi propia transcripción, que presenta algunas variantes respecto de aquella. Para una grabación reciente véase Hirviendo el mar. Spanish Baroque Vocal Music [CD de audio], Vandalia, Rocío de Frutos (dir.), Ars Atlántica, Manuel Vilas (dir.), IBS Classical, 2018. IBS102018, DL GR 114-2018, https://www.youtube.com/watch?v=ryzifF9P07E (consulta 14-5-2020).

${ }^{39}$ A. Vera: Música vocal profana..., pp. 60-64, 110-115; M. Lambea, L. Josa: Libro de tonos humanos (1655-1656). Volumen I; - : Libro de tonos humanos (1655-1656). Volumen II, Madrid-Barcelona, CSIC, 2003; —: Libro de tonos humanos (1655-1656). Volumen III; —: Libro de tonos humanos (1655-1656). Volumen IV, Madrid, CSIC, 2010.

${ }^{40}$ J. Jorquera: Presencia de la música..., p. 231.

${ }^{41}$ A. Vera: Música vocal profana..., pp. 35-42, 64-69, 95-109.

42 Judith Etzion: "The Spanish Polyphonic Cancioneros, c. 1580-c. 1650: A Survey of Literary Content and Textual Concordances", Revista de Musicología, 11, 1, 1988, p. 96.
} 
nombrado secretario real, lo que le garantizaba un estrecho contacto con el monarca. De hecho, en 1624, 1625 y otros años acompañó al rey y su séquito durante sus desplazamientos a Andalucía y Aragón ${ }^{43}$.

Esto explica, en parte, que los cancioneros musicales de la primera mitad del siglo XVII incluyan textos de su autoría ${ }^{44}$, ya que la cámara del rey era uno de los principales espacios para la ejecución de tonos humanos ${ }^{45}$. Incluso, no es aventurado pensar que algunas de las versiones musicales de sus textos fueran producto de una colaboración directa entre Hurtado de Mendoza y los compositores de la corte. Un testimonio de ello parece hallarse en el romance "Oh qué bien descoge al viento", que, como ya advirtió Stein, lleva la indicación "púsole Machado" en la edición póstuma de sus obras completas ${ }^{46}$. En otras palabras, dicho romance fue musicalizado por el compositor portugués Manuel Machado, quien fue contratado como músico de cámara precisamente en $1621^{47}$. Con toda probabilidad, pues, pertenece a Machado la versión musical anónima de "Oh qué bien descoge al viento" que figura en el Libro de tonos humanos ${ }^{48}$.

Otra posible huella del vínculo entre Hurtado de Mendoza y la música podría hallarse en un manuscrito con poemas de su autoría. Quince de estos poemas llevan cifra catalana para guitarra, señal inequívoca de que se cantaban. El manuscrito incluye, además, un breve método de órgano y monocordio, y anotaciones sobre el contexto en el que los textos poéticos fueron escritos. Estas anotaciones aluden mayoritariamente a Aranjuez, el Retiro o representaciones palaciegas, lo que confirma al ámbito cortesano como principal destinatario de los poemas de este autor. Aunque todavía no está claro si el poeta participó, de algún modo, en la confección de esta fuente, es probable que sí lo hiciera a la vista de los datos señalados ${ }^{49}$. Si no fue así, el compilador pudo ser alguien cercano

${ }^{43}$ Gareth A. Davies: "Antonio Hurtado de Mendoza: Biographical Notes", Bulletin of Hispanic Studies, 34, 2, 1957, pp. 79-88.

${ }^{44}$ J. Etzion: "The Spanish Polyphonic...", pp. 87-106. Algunas atribuciones adicionales a Mendoza se hallan en A. Vera: Música vocal profana..., pp. 223-229; M. Lambea, L. Josa: Libro de tonos humanos (16551656). Volumen I; —: Libro de tonos humanos (1655-1656). Volumen II; —: Libro de tonos humanos (1655-1656). Volumen III; —: Libro de tonos humanos (1655-1656). Volumen IV; L. K. Stein: Songs of Mortals..., pp. 371-394.

${ }^{45}$ L. Robledo: Juan Blas de Castro..., pp. 28, 30-46, 53-54, 102-103.

${ }^{46}$ L. K. Stein: Songs of Mortals..., p. 389.

${ }^{47}$ Véase su biografía en A. Vera: Música vocal profana..., pp. 101-103.

${ }^{48}$ Madrid, Biblioteca Nacional de España, M. 1262, ff. 226v-227.

49 Ángel Manuel Olmos, Luisa Morales: "Un nuevo y breve método de órgano y monacordio del siglo XVII en un libro de poemas de Antonio Hurtado de Mendoza", Cinco siglos de música de tecla española: actas de los Symposia FIMTE 2002-2004, Luisa Morales (ed.), Almería, Asociación Cultural Leal, 2007, pp. 207217. Agradezco a Luisa Morales el haberme enviado un ejemplar digital de su texto durante el período de pandemia. Francisco Alfonso Valdivia: Guitarra, sistemas de notación y cultura popular. Los sistemas de notación abreviada de acordes y la popularización de la guitarra en España durante el siglo XVII, tesis doctoral, Universidad de Málaga, 2011, pp. 448-449. El manuscrito original se conserva en la Real Biblioteca del Palacio Real de Madrid, con signatura II/2802 (olim 2-C-10). 
a él, pues varios de los poemas y las anotaciones ni siquiera figuran en la edición póstuma de sus obras, publicada en 1690 y ampliada a comienzos del siglo XVIII ${ }^{50}$.

En suma, el género musical, el autor del texto y el cancionero que lo contiene sugieren que la obra debió ser concebida para un contexto cortesano.Volveremos sobre este aspecto más adelante.

"Heridas en un rendido" ha sido estudiado por Lola Josa y Mariano Lambea, quienes dan cuenta de varios rasgos de interés de esta obra. Como ellos, transcribo a continuación las dos versiones del texto que se han conservado, aunque, por razones que explicaré posteriormente, las presento en el orden inverso al que ellos lo hacen ${ }^{51}$.

Versión del Libro de tonos humanos, ff. 8v-9

Romance

1. Heridas en un rendido nunca son de brazo fuerte, y más flaqueza descubre quien mata, que no quien muere.

\section{A sangre mil veces fría} es, segunda vez, aleve rigor que busca más vida donde no cabe otra muerte.

3. No es crueldad en la hermosura no querer a quien la quiere, sino el ser no más que amada la razón por que aborrece.

4. Amar y ofender amando, ¿qué desdicha lo merece?, ¿y qué puede hacer un alma en un acierto que ofende?

5. Piérdese la vida y alma, y todo llega a perderse por ella, y solo se logra la razón con que se pierde.

\section{Versión de A. Hurtado de Mendo- za: Obras líricas..., pp. 143-144}

Romance

1. Heridas en un rendido nunca fueron de valiente, y más flaqueza descubre quien mata, que no quien muere.

2. A sangre mil veces fría es, segunda vez, aleve rigor que busca más vida donde no cabe otra muerte.

3. No es crueldad en la hermosura no querer a quien la quiere, sino el ser no más que amarla la razón por que aborrece.
4. Piérdase la vida, el alma, y todo llegue a perderse por ella, y solo se logre la razón con que se pierde.

${ }^{50}$ Antonio Hurtado de Mendoza: Obras líricas, y cómicas, divinas, y humanas, con la celestial ambrosía del admirable poema sacro de María Santíssima, último suave divimo aliento de aquel canoro cisne, el más pulido, más affeado, y el más cortesano cultor de las musas castellanas, Madrid, Juan de Zúñiga, [1728].

${ }^{51}$ Lola Josa, Mariano Lambea: "Las 'trazas' poético-musicales en el romancero lírico español", Edad de Oro, 22, 2003, p. 61 . 
6. Si mi muerte, Clori hermosa, es tu gusto, ya la debes a tiernas lágrimas mías primero que a tus desdenes.

7. Si una vida, aun siendo suya, ninguno quitarla puede, ¿Cómo, señora, a tus manos muero yo tan justamente?

8. ¡Qué morir tan desdichado!, sin pena de quien lo siente, sin dolor de quien lo mira, sin triunfo de quien lo vence.

Estribillo:

Fuego en la nieve, que abrasando se hiela de lo que enciende.

Fuego mil veces, en belleza que vive de matar siempre.
5. Hoy mi muerte, Anfrisa hermosa, si es tu gusto la desees, mírale en lisonjas mías, primero que en tus desdenes.
Estribillo:

Fuego en la nieve, y en belleza que vive de matar siempre.

Resultan evidentes las diferencias entre ambas versiones: la de las Obras líricas tiene menos estrofas y aquellas que coinciden presentan variantes; además, se modifica la extensión del estribillo. Sin embargo, coincido con Josa y Lambea cuando afirman que la versión del Libro de tonos humanos, por su calidad, debe haber sido escrita por el propio Hurtado de Mendoza o al menos por otro poeta de su mismo nivel ${ }^{52}$.

En una primera lectura, el poema reproduce un tópico frecuente en la poesía del Siglo de Oro que López Cano designa como "deseo del rigor", según el cual el dolor se entiende como parte esencial del proceso amatorio ${ }^{53}$. En el caso de "Heridas en un rendido", el dolor lo provoca la indiferencia de la amada, que no solo desdeña al amante con frialdad (estrofa 2), sino que parece disfrutar cuando lo hace (estrofa 6). Sin embargo, el amante le recrimina que herir a quien ya ha sido vencido no tiene mérito alguno: por el contrario, devela la "flaqueza" de quien lo hace (estrofa 1$)^{54}$.

Josa y Lambea agregan que la séptima cuarteta ("Si una vida...”) está en una relación de antítesis con la sexta ("Si mi muerte...") y termina con una interrogación retórica, de las varias que hay en el romance.Además, la octava y

\footnotetext{
52 L. Josa, M. Lambea: “Las 'trazas' poético-musicales...”, p. 35.

${ }^{53}$ R. López Cano: De la retórica a la ciencia cognitiva..., pp. 761-762.

${ }^{54} \mathrm{Al}$ indicar la numeración de las estrofas, remito siempre a la versión del Libro de tonos humanos.
} 
última estrofa concluye con una sucesión de tres versos y exhibe una estructura anafórica, todo lo cual conduce al desbordamiento "de ese desdén sufrido desde el olvido y el silencio" 55 .

La música del tono no es menos interesante que el texto. La pieza está escrita, según la nomenclatura de la época, en el "cuarto tono natural", que tiene su final (o nota principal) en Mi y su mediación (o nota secundaria) en La. No obstante, si creemos a Lorente (1672), los villancicos compuestos en este tono se escribían normalmente "por la mediación" y solo ocasionalmente "por el final"; es decir, solían comenzar y concluir en $\mathrm{La}^{56}$. Dada la afinidad ya comentada entre el tono y el villancico, no sorprende que así ocurra en esta obra.

Si la mayoría de las piezas contenidas en el Libro de tonos humanos se inicia con una textura homofónica ${ }^{57}$, este romance comienza con una imitación a cuatro voces a intervalos de octava y quinta. Este inicio es reminiscente del género del lamento, cuyas características hemos visto en la introducción, no solo por la reiteración del intervalo de segunda menor, ya advertida por Josa y Lambea ${ }^{58}$, sino porque la entrada del bajo da lugar a un tetracordio descendente que transcurre en valores largos y retardos. Además, en los compases 5-6 hay una cadencia frigia (o "cláusula remisa") ${ }^{59}$, como es frecuente en dicho género ${ }^{60}$ (ejemplo 2).

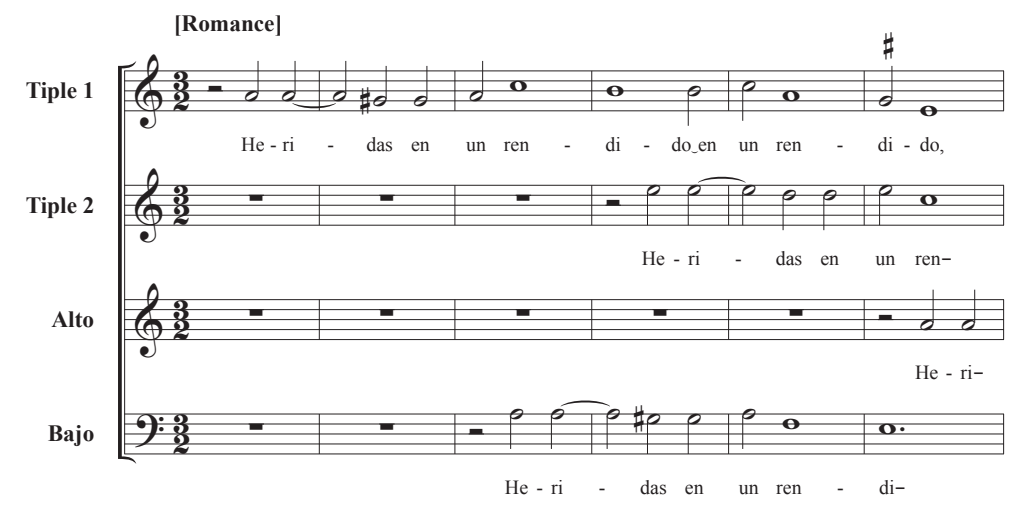

Ejemplo 2. Cadencia frigia en el tono "Heridas en un rendido"

\footnotetext{
${ }^{55}$ L. Josa, M. Lambea: "Las 'trazas' poético musicales...", p. 36.

${ }^{56}$ Andrés Lorente: El porqué de la música, Alcalá de Henares, Nicolás de Xamares, 1672, pp. 563, 621. Sigo a este autor por su importancia y cercanía con la época de compilación de la obra.

${ }^{57}$ A. Vera: Música vocal profana..., pp. 165, 238-239.

${ }^{58}$ L. Josa, M. Lambea: "Las 'trazas' poético-musicales...", p. 56.

${ }^{59}$ Según la nomenclatura de la época. Véase A. Lorente: El porqué de la música, p. 240.

${ }^{60}$ Cristóbal L. García Gallardo: "La imagen de Andalucía en la teoría de la música: la cadencia andaluza", Andalucía en la música. Expresión de comunidad, construcción de identidad, Francisco José García Gallardo, Herminia Arredondo Pérez (coords.), Sevilla, Junta de Andalucía, 2014, p. 117.
} 
A este carácter lamentoso del romance corresponde la séptima en primera inversión que figura más adelante (c. 13), en el verso "nunca son de brazo fuerte" ${ }^{61}, \mathrm{y}$ el salto ascendente de cuarta disminuida en el tiple primero, al final de la cuarteta, cuando las voces cantan "quien mata, que no quien muere" (cc. 25-26) ${ }^{62}$. Este último era un recurso típico de la época para expresar la lamentación o infelicidad ${ }^{63}$.

El estribillo, cuya estructura poética responde al modelo formal de la seguidill $^{64}$, se inicia con un compás de silencio (c. 28) en todas las voces ${ }^{65}$, pero a partir del compás siguiente estas resurgen cantando "Fuego en la nieve", con un ímpetu musical que parece sugerir "una resurrección" 66 . De hecho, este inicio recuerda al tópico de la música de batalla, frecuentemente empleado en este tipo de música, por el uso de "acordes" ${ }^{67}$ mayores que se repiten al modo de una fanfarria y oscilan a distancia de quinta descendente (cc. 29-32 ${ }^{68}$. Sin embargo, en el pasaje que sigue la textura se adelgaza y el tiple primero canta a solo "que abrasando se hiela / de lo que enciende" (cc.33-41), quizá para que el oyente comprenda bien este oxímoron que, como veremos, es más significativo de lo que parece a primera vista. Luego, las voces retoman el texto desde el inicio y, mientras el verso "Fuego en la nieve" da lugar nuevamente al tópico de batalla, el verso "que abrasando se hiela" se canta ahora mediante una imitación a cuatro voces. Además, el compositor emplea una séptima en primera inversión sobre el acento principal de este verso en dos ocasiones (cc. 51 y $55)^{69}$, quizá para remarcar el oxímoron ya señalado.

${ }^{61}$ Dado que esta disonancia coincide con el acento principal del segundo verso y, por ende, con la primera asonancia, podría atribuírsele también una función estructural similar a las que Pelinski ha descrito para el Cancionero de Sablonara (véase estado de la cuestión).

${ }^{62}$ Este último es mencionado también por L. Josa, M. Lambea: "Las 'trazas' poético-musicales...", p. 53.

${ }^{63}$ R. López Cano: Música y retórica..., pp. 154-155.

${ }^{64}$ Véase, sobre la importancia de la seguidilla en los estribillos de los tonos humanos, Álvaro Torrente: "Tonos, bailes y guitarras: la música en los ámbitos privados", Historia de la música en España e Hispanoamérica. 3. La música en el siglo XVII, Álvaro Torrente (ed.), Madrid, Fondo de Cultura Económica de España, 2016, pp. 210-213; G. Arriaga: José Marín..., pp. 88-99.

${ }^{65}$ L. Josa, M. Lambea: "Las 'trazas' poético-musicales...", p. 55, opinan que este silencio inicial explica, hermenéuticamente, que "el silencio tras la muerte es el mismo silencio que antes de la vida". Cabría tener presente, sin embargo, que las obras del Libro de tonos humanos parecen haber contado con algún tipo de acompañamiento instrumental, pese a no estar escrito en la fuente. A. Vera: Música vocal profana..., p. 151-160.

${ }^{66}$ L. Josa, M. Lambea: "Las 'trazas' poético musicales...", p. 36.

${ }^{67}$ En este trabajo, utilizo el término "acorde" para referirme a tres o más notas agrupadas verticalmente. Otros autores prefieren conceptos como "sonoridad" o "postura", para evitar el anacronismo, pero creo que hablar de "acorde" facilita la comunicación con el lector actual y que, si se entiende en el sentido señalado, no es tan distante al pensamiento musical de la época. Aun así, empleo comillas para indicar que no se trata de acordes en el sentido que les atribuye la armonía funcional.

${ }^{68}$ Sobre la música de batalla, véase, entre otros, Craig H. Russell: Santiago de Murcia: Spanish Theorist and Guitarist of the Early Eighteenth Century, tesis doctoral, University of North Carolina at Chapel Hill, 1981, pp. 259-265; B. Illari: Polychoral Culture..., pp. 288-295.

${ }^{69}$ L. Josa, M. Lambea: “Las 'trazas' poético-musicales...”, p. 53. 
Concluido lo anterior, que constituye la primera parte del estribillo en términos literarios, las voces exclaman "Fuego mil veces", en una imitación a tres voces acompañada por el bajo. El compositor evoca, por tercera vez, el tópico de batalla (cc. 61-66) y utiliza el mismo motivo melódico del comienzo del estribillo, pero invertido, algo que podría relacionarse con las numerosas paradojas que el texto contiene. Entonces, la composición vuelve al tono lamentoso del romance, pues los versos "en belleza que vive / de matar siempre" se cantan mediante una estupenda imitación a cuatro voces, sobre un motivo descendente que da lugar a retardos y a una cadencia frigia o "remisa" (cc. 67-88) ${ }^{70}$. Así, la mayor parte de este tono humano queda embebida de motivos que para un oyente del siglo XVII estarían vinculados al dolor y a la tristeza. Además, esta secuencia imitativa incluye un motivo incisivo (mínima con punto-semínima) que pasa de una voz a otra y rompe con la acentuación propia del compás, procedimiento que recuerda a algunos tonos de fray Manuel Correa (ejemplo 3) ${ }^{71}$.

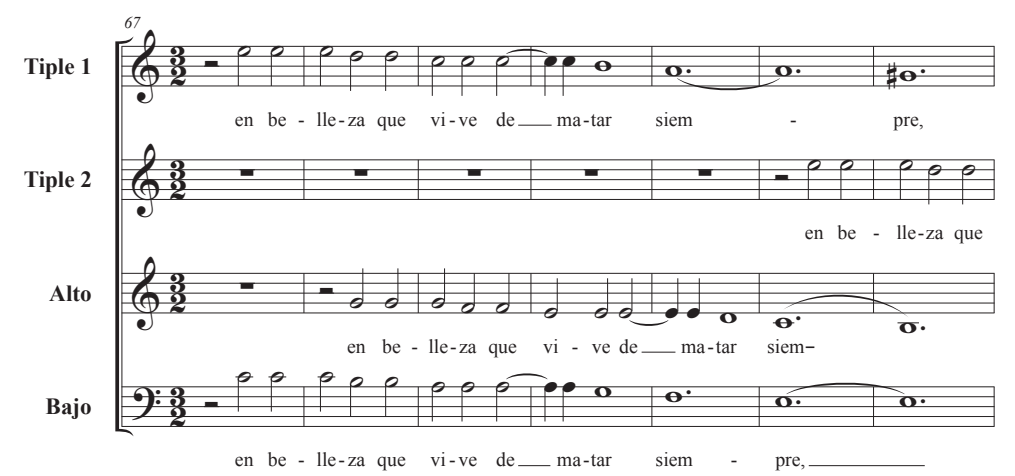

Ejemplo 3. Imitación a cuatro voces en el tono "Heridas en un rendido"

\footnotetext{
${ }^{70}$ Quizá no sea casualidad que este motivo se asemeje al primero de los patrones métricos que Torrente atribuye a la "seguidilla primitiva", ya que, como hemos visto, el texto del estribillo responde a esta forma poética. A. Torrente: "Tonos, bailes y guitarras...", p. 212. El hecho de que el compositor asigne un único motivo a la pareja de versos heptasilabo y pentasílabo es también propio de la seguidilla. G. Arriaga: José Marín..., p. 88.

71 "Amad sin premio zagales" (cc. 45-56, 81-90) y "Miente la vista, que al cielo" (cc. 78-96), en A. Vera: Música vocal profana..., pp. 355-357, 387-388. Sin perjuicio de lo incierta que suele resultar la atribución estilística, no sería extraño que "Heridas en un rendido" fuese de Correa. Ya advirtió Pedrell, en su estudio pionero sobre esta fuente, que, aparte de las piezas atribuidas a dicho compositor, había muchas otras que acusaban su estilo. F. Pedrell: Teatro lírico..., vol. 3, p. XXXI. Cabe señalar que esta posibilidad no contraviene el vínculo entre esta pieza y la corte. Un testimonio motivado por el fallecimiento del carmelita en 1653, afirma que era "el primero en gracia para los villancicos, que con ser obra suya, quedaba para Su Majestad y para toda España aprobada", lo que sugiere que su música debió interpretarse en la corte y era apreciada por Felipe IV. Pedro Calahorra: La música en Zaragoza, Zaragoza, Institución Fernando el Católico, 1978, vol. 2, p. 101. Además, Correa efectivamente puso en música otros poemas de Hurtado de Mendoza: los tonos "Flores, que más florecientes", "Hola pastor que a la orilla" y "Qué alegre de verse triste". A. Vera: Música vocal profana..., pp. 223-224, 227.
} 
No obstante, el pasaje más chocante tiene lugar al final de la obra. Luego de un breve fragmento que retoma el cuarto verso del estribillo ("Fuego mil veces", cc. 87-95), las voces exclaman, por última vez, "En belleza que vive / de matar siempre" y la pieza concluye en un "acorde" de La mayor. Esto último no tiene nada de especial, por tratarse de la mediación del cuarto tono natural, como ya hemos explicado. Pero, en lugar de alcanzarlo mediante un semitono ascendente en alguna de las voces superiores (de Sol sostenido a La) y una caída de quinta en el bajo (de Mi a La), como cabría esperar ${ }^{72}$, el tiple primero desciende un semitono y el bajo asciende un tono. Además, el penúltimo "acorde" es una séptima en primera inversión, con la particularidad de que la quinta disminuida no se produce desde el bajo (Sol natural), como es usual en este repertorio, sino entre las voces superiores, por haber un Si bemol en el tiple primero (ejemplo 4).

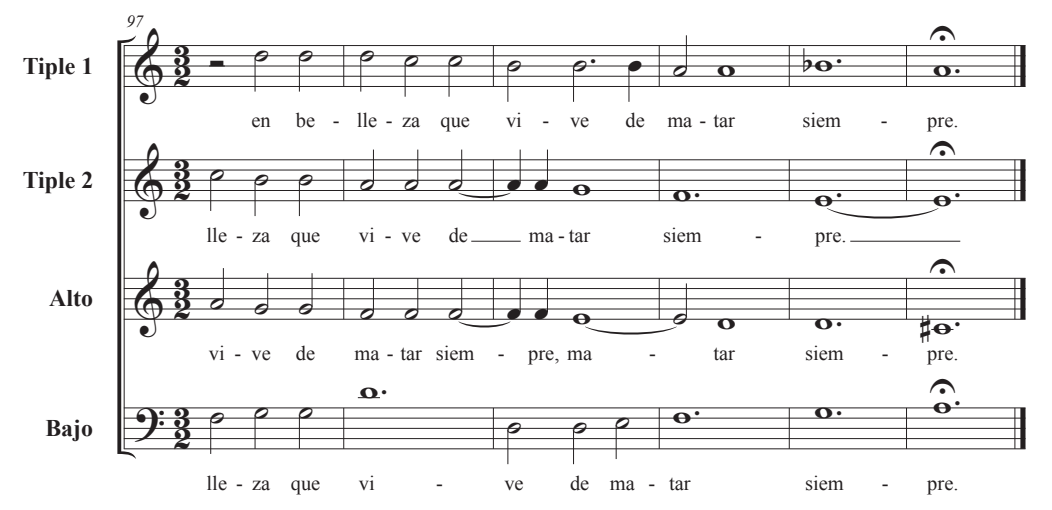

Ejemplo 4. Cadencia final en "Heridas en un rendido"

Josa y Lambea no dejan de advertir la peculiaridad de esta cadencia ${ }^{73}$, pero creo que el pasaje es aún más singular de lo que ellos señalan. De las 222 piezas incluidas en el Libro de tonos humanos, solo tres concluyen con una cadencia en la que el bajo asciende un tono ${ }^{74}$. En "Pastorcillo triste" (ff. 131v-132), de Carlos Patiño, y "No quiero más burlas Juana” (ff. 155v-156), anónimo, dicho

72 Esta es la "cláusula" que Lorente prescribe para la mediación del tono. A. Lorente: El porqué de la música, p. 563; G. Arriaga: José Marín..., p. 161. En términos actuales sería una cadencia auténtica, aunque el término resulte discutible no solo por ser anacrónico, sino porque los grados involucrados no son precisamente el quinto y el primero.

${ }^{73}$ Los autores señalan que la composición concluye "sin cláusula al uso". L. Josa, M. Lambea: "Las 'trazas' poético-musicales...", pp. 53-54.

${ }^{74}$ El resto de las cadencias se distribuye así: en 195 piezas el bajo desciende una quinta (auténticas); en 16 asciende este mismo intervalo (plagales); en cuatro desciende una segunda menor (frigias), y en otras cuatro asciende un semitono. Fuente: Madrid, Biblioteca Nacional de España, M. 1262. 
intervalo se produce tras una nota de paso ascendente entre $\mathrm{IV}_{6}$ y I. Pero en "Heridas en un rendido" la disonancia y la alteración ya señaladas convierten a su cadencia final en un caso único en el manuscrito.

Por otro lado, el Si bemol, además de ser único en la pieza ${ }^{75}$, constituye para la época la antítesis del Sol sostenido que, teóricamente, debería figurar antes del $\mathrm{La}^{76}$. Además, el tipo de cadencia que produce podría interpretarse como una variante de la "cláusula remisa" o frigia ${ }^{77}$. Por tanto, esta cadencia constituye un gesto paradójico que se suma a los que el texto contiene: Si bemol en lugar de Sol sostenido; descenso -en lugar de ascenso- de semitono; “ "cláusula remisa" en lugar de "sostenida".

Un gesto tan peculiar debe necesariamente ir aparejado con un significado igualmente especial. De hecho, Nassarre afirma en su Escuela música que la cláusula en la mediación del cuarto tono solo podía ser "remisa" o frigia "en algún caso especial, si conviniere así por razón de expresar el afecto de la letra, o por otra circunstancia" 78 . Pero, ¿cuál pudo ser el significado en este caso? Siguiendo la tendencia ya comentada en el estado de la cuestión, podríamos atribuirlo al oxímoron que figura en los dos versos finales del estribillo, dado el gusto de la estética barroca por la paradoja y el contraste. Otra opción sería seguir a Josa y Lambea e interpretarlo como una forma de representar la muerte $^{79}$, pero esta constituye un tópico relativamente frecuente en los tonos del siglo XVII, sin que suela dar lugar a pasajes tan extraños como el presente.

Recordando, pues, las reflexiones iniciales en torno al aviso de 1662 citado en la introducción, propongo que en este y otros tonos de la época las disonancias y los gestos más llamativos suelen coincidir con los oxímoros y otras figuras paradójicas, pero no solo por la necesidad de destacar el contraste, sino sobre todo porque se trata de equívocos, que contienen la clave para descifrar el sentido del poema. Después de todo, hemos visto que Gracián contemplaba la posibilidad de explicar el equívoco "con otra palabra contraria...".

${ }^{75}$ Antes, en la cuarteta (c. 20), hay dos Si naturales en el bajo que Lambea y Josa sugieren bemolizar en su edición. L. Josa, M. Lambea: Libro de tonos humanos (1655-1656). Volumen I, p. 111. Pero la alteración no está escrita en el original y no parece imprescindible de acuerdo con la preceptiva de la época (el Si sube al Do y vuelve a bajar). Por estas razones, he preferido no incluirla en mi transcripción (v. apéndice).

${ }^{76}$ Nassarre, en su primer tratado, publicado originalmente en 1683, prohíbe emplear el Sol sostenido en tonos que tengan Si bemol en su armadura, por la disonancia de tercera disminuida que se produciría entre ambas notas y porque una "cláusula" con Sol sostenido implicaría salir del tono. Pablo Nassarre: Fragmentos músicos repartidos en quatro tratados, Madrid, Imprenta de Música, 1700, pp. 120-121.

${ }^{77}$ Así al menos la interpreta Salvador Valenzuela: Armonía modal, modo de Mi y flamenco. Aproximación al 'Modo de Mi armónico' como sistema musical de tradición hispana, tesis doctoral, Universidad de Granada, 2016, pp. 151, 272.

${ }^{78}$ Pablo Nassarre: Segunda parte de la Escuela música, Zaragoza, Herederos de Manuel Román, 1723, p. 368. Las cursivas son mías. Este pasaje confirma que la cláusula sostenida es la más propia para la mediación del cuarto tono, tal como Lorente afirma en su tratado. Véase nota al pie 72.

${ }^{79}$ L. Josa, M. Lambea: “Las 'trazas' poético-musicales...”, p. 36. 
$\mathrm{Al}$ respecto, pueden resultar iluminadores otros ejemplos que se hallan en el propio Libro de tonos humanos. Quizá el más relevante sea uno que hemos citado en el estado de la cuestión. Al final del tono "Con rigores premia Filis", de Murillo, una séptima en primera inversión se resiste a resolver mientras el yo poético exclama "Dándome muerte / Filis me da vida". Pero ¿cómo es posible que ella le dé muerte y vida al mismo tiempo? La explicación es que, desde el siglo XV, la poesía española solía utilizar el verbo morir y algunas expresiones derivadas del mismo ("dar muerte", "perder la vida") como alegoría del orgasmo ${ }^{80}$. Esto se torna aún más evidente en el tono de Murillo si se considera otro pasaje del estribillo (cc. 51-58), en el que el tiple primero exclama repetidas veces "jay, qué favor, qué favor..." mientras ejecuta una progresión ascendente, en lo que constituye una clara imitación de la excitación creciente del acto sexual. Quizá no por casualidad lo que hoy llamamos progresión era conocido en la teoría germana de la época como gradatio o climax (ejemplo 5) ${ }^{81}$. Por tanto, Filis da vida al amante cada vez que lo "mata".

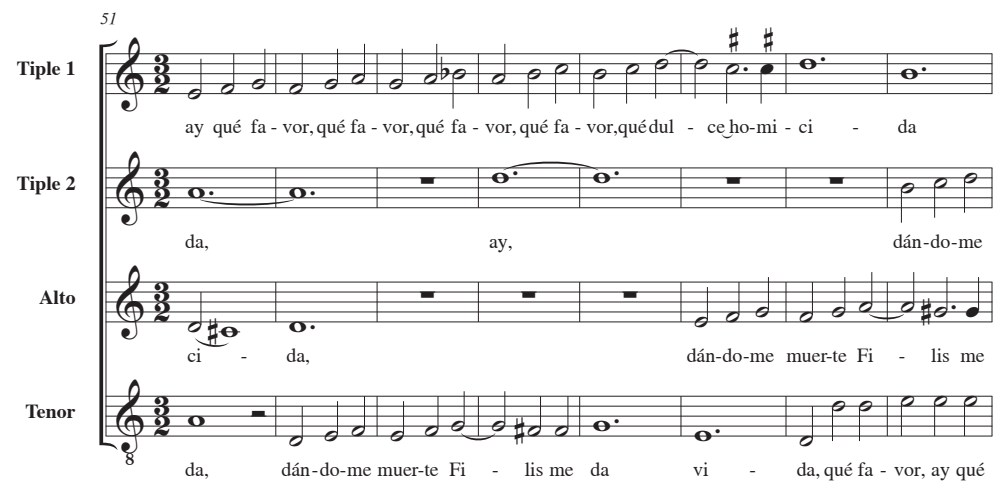

Ejemplo 5. Progresión ascendente en el tiple primero, del tono "Con rigores premia Filis", de fray Bernardo Murillo

Un caso similar parece hallarse en el tono "Para qué quiero la vida", de fray Manuel Correa (ff. 55v-56), que presenta una disonancia poco frecuente en el

${ }^{80}$ Véase, entre otros, Ian Macpherson: "Secret Language in the Cancioneros: Some Courtly Codes", Bulletin of Hispanic Studies, 62, 1985, p. 54; Bienvenido Morros: "Concepto y simbolismo en la poesía del Cancionero General", Revista de Literatura Medieval, 12, 2001, pp. 207-209, 217, 225.

${ }^{81}$ R. López Cano: Música y retórica..., pp. 121-123. La idea de la muerte como alegoría del orgasmo está presente incluso en el lenguaje popular actual. En francés, por ejemplo, se habla de la "petite mort". En la poesía contemporánea, un bello ejemplo se halla en la "Gacela del amor desesperado" de Federico García Lorca: “... Ni la noche ni el día quieren venir / para que por ti muera / y tú mueras por mí”. 
bajo, al final del estribillo, en los versos " $¡ O$ Oh, qué alegre vives / cuando muero yo!" ${ }^{2}$. Incluso, algunos pasajes del romance sugieren de forma aún más explícita que se está hablando del acto sexual ${ }^{83}$.

Volvamos ahora a "Heridas en un rendido" para ver cómo el texto adquiere un nuevo sentido que, sin anular al anterior, contribuye a comprender la pieza en su doble significado: "en belleza que vive / de matar siempre". En efecto, nuestro amante se ha enamorado de una prostituta, cuya subsistencia depende de los orgasmos que provoca a quienes la frecuentan. Lo que parecía a primera vista un poema más sobre la tristeza por el amor no correspondido, manifiesta ahora claras connotaciones sexuales:

- El amante tiene relaciones una y otra vez con la amada, pero su desgracia consiste en que, mientras él experimenta una excitación irresistible, no consigue provocar en ella sensaciones similares, ni menos llevarla a alcanzar el orgasmo: solo él es quien muere ("A sangre mil veces fría / es, segunda vez, aleve / rigor que busca más vida / donde no cabe otra muerte");

- Al mismo tiempo, se encuentra incómodo y contrariado porque, aunque la ama genuinamente, siente que la deshonra al usar su cuerpo como fuente de placer a cambio de dinero ("Amar y ofender amando / ¿qué desdicha lo merece?...”);

- $\quad$ Sin embargo, y aquí yace una de las paradojas, pese a esta contrariedad $\mathrm{y}$ al hecho de no ser correspondido por ella, no siente pena alguna en el momento de morir, sino al contrario (" $\mathrm{QQué} \mathrm{morir} \mathrm{tan} \mathrm{desdichado!,}$ / sin pena de quien lo siente...").

En este mismo sentido podemos interpretar el texto del estribillo:

- "Fuego en la nieve" constituye una metáfora de la excitación que el amante experimenta ante la total indiferencia de su amada;

- Y "que abrasando se hiela / de lo que enciende" refiere a la frialdad que sobreviene al clímax sexual ${ }^{84}$.

${ }^{82}$ Se trata de una nota de paso en el bajo, pero que se prolonga una semibreve. L. Josa, M. Lambea: Libro de tonos humanos (1655-1656). Volumen I, pp. 83, 276.

${ }^{83}$ Por ejemplo, "Por dicha tengo el morir, / y, aunque es terrible remedio, / al fin es mejor, pues no / es estar siempre muriendo". L. Josa, M. Lambea: Libro de tonos humanos (1655-1656). Volumen I, p. 59.

${ }^{84}$ Lola Josa, en línea con su lectura del texto, interpreta este oxímoron en el sentido de que la dama enamora, pero "es desdeñosa con ese amor". L. Josa, M. Lambea: Libro de tonos humanos (1655-1656). Volumen I, p. 37. 
Dos detalles más pueden ser de interés para esta interpretación. Uno de ellos es que el sustantivo "herida" se utiliza para aludir a la relación sexual en algunos poemas del Cancionero genera ${ }^{\beta 5}$. El otro tiene que ver con la mención a "Clori”, al inicio de la sexta estrofa. Es posible, como proponen Josa y Lambea, que se trate de una referencia a la Clori o Cloris que aparece con frecuencia en la poesía gongorina ${ }^{86}$. Pero "Cloris" es además el nombre griego de "Flora" y, en ciertos relatos de la época, este nombre identifica no solo a la diosa de las flores, sino a la patrona de las prostitutas ${ }^{87}$. Así, el nombre "Clori" podría constituir una alusión velada al oficio de la amada.

La afirmación de que el Libro de tonos humanos incluye textos con contenido sexual o erótico no constituye una novedad.Ya decía Pedrell, el primero en estudiar esta fuente, que "la letra de algunos tonos, especialmente los del P. Correa y del P. Murillo, avergonzaría a un coracero" 88 . Pero lo llamativo es el grado de sofisticación con el que se manifiesta el erotismo en esta obra. Desde el punto de vista semiológico, la peculiar cadencia que el compositor emplea al final de "Heridas en un rendido" constituiría un signo que desempeña una doble función. Por un lado, la disonancia que incluye resulta dificil de comprender para la teoría de la época, lo que representa el carácter enigmático del texto mediante una relación de semejanza; así mismo, el hecho de que la cadencia sea contraria a la que se emplea normalmente en el cuarto tono natural resulta análogo al carácter paradójico del texto - se trataría pues de un ícono, para la semiótica peirceana ${ }^{-89}$. Por otro lado, el pasaje está destinado a llamar la atención del oyente sobre el oxímoron final; le indica que debe ir más allá del significado literal si quiere comprender su sentido, y que en el oxímoron yace la clave para descubrirlo -desde este punto de vista, se trataría de un índice y, más precisamente, de un índice por deixis-90. Así, música y texto, imbricadamente, proporcionan las pistas para que un "escucha competente" -volveré a esto en la sección siguiente- pueda comprender la obra en su doble significación.

\footnotetext{
${ }^{85}$ B. Morros: "Concepto y simbolismo...", p. 208.

${ }^{86}$ L. Josa, M. Lambea: "Las 'trazas' poético-musicales...", p. 35.

${ }^{87}$ Carmela V. Mattza: "Écfrasis y mitología en La vida es sueño: el mito de Céfiro y Cloris", Anuario Calderoniano, 8, 2015, pp. 315-322.

${ }^{88}$ F. Pedrell: Teatro lírico..., vol. 3, p. XXXII.

${ }^{89}$ A esta función icónica alude Nassarre cuando recomienda emplear "falsas" o disonancias poco usuales sobre "palabras muy misteriosas de las muchas que hay en el oficio divino y en el santo sacrificio de la misa...". P. Nassarre: Segunda parte de la Escuela..., p. 313.

${ }^{90}$ Según Peirce, el ícono es un tipo de signo que remite a su objeto en virtud de una semejanza, mientras que el índice lo hace por medios diversos. Uno de estos, la deixis, consiste en el uso de partículas que solo adquieren significado en un contexto específico; por ejemplo, cuando un diseño melódico se ha repetido consistentemente de una forma y de pronto se modifica. Desde luego, estas funciones pueden combinarse, como ocurre en este caso. R. López Cano: De la retórica a la ciencia cognitiva..., pp. 387-393, 559 (esta última sobre el "tópico ícono-indexical"). H. Beristáin: Diccionario..., pp. 455-458.
} 
Para concluir este apartado, quisiera aclarar un punto que había quedado pendiente: mi decisión de transcribir la versión del Libro de tonos humanos antes que aquella incluida en las Obras líricas... de Hurtado de Mendoza.Josa y Lambea lo hacen a la inversa porque piensan que esta última constituye el hipotexto u original, es decir, que el poeta y el músico elaboraron su versión basándose en aquella que posteriormente fue impresa, a la que cambiaron una que otra palabra o frase y agregaron estrofas nuevas ${ }^{91}$. Pero no hay ninguna razón para asegurar que realmente fuese así. Más aún, lo que conocemos acerca de los romances cortesanos sugiere que, con no poca frecuencia, estos eran cantados durante varios años antes de ser publicados. Por ejemplo, el príncipe de Esquilache, otro poeta que estuvo estrechamente ligado a la corte (fue gentilhombre de cámara de Felipe IV) y cuya obra literaria fue editada en sus últimos años de vida, se refería así a los romances de su autoría:

Otros reyes os oyeron, y de nuestro gran Felipe acompañastes las fiestas, las noches entretuvistes ${ }^{92}$.

A esto se añade que las Obras líricas... de Hurtado de Mendoza fueron editadas casi cincuenta años después de su fallecimiento, lo que hace aún más incierto que contengan siempre las versiones más cercanas a las que él mismo escribió.

Parece probable, pues, que la versión del Libro de tonos humanos constituya la “original" o, al menos, la versión más próxima al contexto de producción. Si esto es correcto, en la versión impresa se optó por cercenar parcialmente el texto y modificar algunos pasajes. Por ejemplo, tanto la cuarta estrofa ("Amar y ofender amando...") como la octava (“... sin pena de quien lo siente...") fueron suprimidas, quizá por ser las que contenían los elementos más explícitos para inferir el carácter erótico del texto y el oficio al que se dedicaba la amada. Así mismo, la sustitución de "Clori" por "Anfrisa", en la estrofa seis, podría deberse a las asociaciones ya comentadas entre aquella y la prostitución. Finalmente, los tres versos que se quitaron al estribillo ("que abrasando se hiela / de lo que enciende. / Fuego mil veces...") hacían aún más evidente la connotación sexual del texto. Por tanto, es probable que el poema fuese modificado para dificultar la comprensión de su sentido erótico y adecuarlo así al decoro que se esperaba de una edición impresa a fines del Siglo de Oro.

\footnotetext{
${ }^{91}$ Procedimiento que ellos denominan "traza por amplificación”. L. Josa, M. Lambea: "Las 'trazas' poético-musicales...", p. 35.

${ }^{2}$ Francisco de Borja y Aragón [príncipe de Esquilache]: Las obras en verso de don Francisco de Borja, Amberes, Imprenta Plantiniana de Balthasar Moreto, 1654 (2. a ed.), p. 561.
} 


\section{Las "circunstancias o adjuntos del sujeto"}

Es evidente que los procedimientos descritos resultan afines a la preceptiva de la dificultad que caracterizó a la cultura del Barroco. Decía Luis Alfonso de Carvallo, citado por Maravall, que:

de ver las cosas muy claras se engendra cierto fastidio, con que se viene a perder la atención y así se leerá un estudiante cuatro hojas de un libro, que por ser claro y de cosas ordinarias no atiende a lo que lee. Mas si es dificultoso y extraordinario su estilo, esto propio lo incita a que trabaje por entendello, que naturalmente somos inclinados a entender y saber y un contrario con otro se esfuerza, ansí con la dificultad crece el apetito de saber ${ }^{93}$.

Así mismo, el ya citado Gracián afirmaba: "A más dificultad más fruición del discurso en topar con el significado, cuando está más oscuro"; y también: "La verdad, cuanto más dificultosa, es más agradable, y el conocimiento que cuesta es más estimado" 94 . Por esta razón, es muy probable que otros tonos de la época $-\mathrm{y}$ también villancicos- exhiban recursos similares a los que hemos estudiado. Por el momento, hemos podido constatar que al menos dos piezas del Libro de tonos humanos, una de Murillo y otra de Correa, presentan procedimientos retóricos afines a los de "Heridas en un rendido" $"$. En todas ellas el pasaje musical más llamativo figura al final, cuando el texto presenta un oxímoron; pero esto no solo se debe al interés de la estética barroca por el contraste, como suele afirmarse, sino a que el oxímoron encierra además un equívoco, que contiene la clave para comprender el sentido oculto -en este caso erótico- del texto. Queda, pues, pendiente la pregunta de cuán frecuente era este procedimiento en el repertorio vernáculo español del siglo XVII.

Sin perjuicio de todo ello, vale la pena preguntarse, antes de concluir, si los equívocos empleados en "Heridas en un rendido" pudieran relacionarse con lo que Gracián llamaba "las circunstancias o adjuntos del sujeto", algo que, a juicio de este autor, les daba aún "mayor artificio" (véase la Introducción). Aunque este ejercicio conlleve una dosis importante de especulación, puede contribuir a incrementar nuestra comprensión de la cultura musical de la época. Además, ya se ha comentado que la historia, en cualquiera de sus formas, implica siempre algún grado de incertidumbre ${ }^{96}$.

\footnotetext{
${ }^{93}$ José Antonio Maravall: La cultura del Barroco. Análisis de una estructura histórica, Barcelona, Ariel, 1975, pp. 443-444.

${ }^{94}$ J. A. Maravall: La cultura del Barroco..., p. 444, 449 y ss.

${ }^{95}$ Esto podría constituir otro indicio acerca de la posible autoría de Correa, que ya hemos comentado. Véase la nota al pie 71.

${ }^{96}$ Véase la nota al pie 9.
} 
Hemos visto que tanto la autoría de Hurtado de Mendoza como la conservación de la pieza en el Libro de tonos humanos sugieren que esta fue escrita para el ámbito cortesano. Esto no es de extrañar, puesto que, según Stein, gran parte de la literatura y la música eróticas del siglo XVII fue comisionada por -o dedicada a- la nobleza, cuyos miembros eran educados para comprender su sentido. Esto era relevante porque, si muchos de los textos estaban al borde de lo pornográfico, solían expresarlo mediante "un pesado velo de metáforas" y referencias a la mitología clásica. Aun así, con frecuencia aludían también a personajes y situaciones reales, tomados de su propio contexto de producción - por ejemplo, un matrimonio de importancia- ${ }^{97}$.

Pero ¿quién podría ser el amante despechado en el caso de "Heridas en un rendido"? Una posibilidad es que fuese el propio Hurtado de Mendoza, describiendo alguna de sus eventuales andanzas en los burdeles. Sin embargo, existe otra alternativa aún más interesante: que fuese Felipe IV. Esta opción parece probable por varias razones: los tonos de la corte eran con frecuencia escritos para el monarca (véase el testimonio de Esquilache ya citado); Hurtado de Mendoza tenía cercanía con él por ser su secretario personal, y, sobre todo, son de sobra conocidas las infidelidades del rey, sus relaciones con mujeres de la más diversa condición -desde damas nobles a actrices o "busconas"- y sus numerosos hijos "naturales" 98 . De hecho, algunos poemas de Quevedo contienen pasajes que, pese a estar escritos en tono de broma, presentan a Felipe IV casi como un conocido proxeneta, que en los eventos públicos capta la atención de todas las prostitutas de la ciudad ${ }^{99}$. Relatos de este tipo sirvieron de inspiración a Torrente Ballester para escribir su Crónica del rey pasmado, novela histórica que se inicia cuando el rey, acompañado por un enigmático conde de Peña Andrada, comete adulterio con Marfisa, la prostituta más bella de toda la villa ${ }^{100}$.

Cabe recordar aquí la profunda crisis social y degradación moral en las que se hallaban sumidas España y su corte en el siglo XVII; una degradación que el rey mismo acabaría protagonizando, pese a haber intentado, al comienzo de su regencia, poner límites a la corrupción generalizada.Y, sin embargo, las fiestas, el teatro y el arte en general experimentaron un singular florecimiento bajo su

${ }^{97}$ Louise K. Stein: "Eros, Erato, Terpsíchore and the Hearing of Music in Early Modern Spain", The Musical Quarterly, 82, 3/4, 1998, pp. 656, 672-673.

${ }^{98}$ Félix Cantizano Pérez: "De las ninfas del Olimpo a las ninfas de las tasqueras: una visión de la prostitución en la España del Siglo de Oro", eHumanista, 15, 2010, p. 164.

${ }_{99}$ Posiblemente fueran una crítica velada, pues se publicaron en la misma época en la que se hizo público el mencionado amorío del rey con la Calderona. Rafael Iglesias: "Una posible nueva interpretación de los poemas de Quevedo de principios del reinado de Felipe IV relativos a fiestas de toros y de cañas", Journal of the Society for Renaissance and Baroque Hispanic Poetry, 10, 2, 2004, pp. 85-87.

${ }^{100}$ Gonzalo Torrente Ballester: Crónica del rey pasmado, Barcelona, Planeta, 1989. 
reinado, en parte porque creaban "la ilusión de que aún queda[ba] riqueza y poder" ${ }^{101}$. El arte barroco, en su conjunto, servía no solo para retratar lo más sublime del ser humano, sino también sus miserias ${ }^{102}$.

Desde luego, aun aceptando que Felipe IV pudiera ser el protagonista de "Heridas en un rendido", no puede descartarse que la mujer aludida fuese de otra condición - por ejemplo, una comediante o alguna joven de la corte que despertaba su pasión-. Sin embargo, parece probable que los versos finales del estribillo constituyan una alusión al oficio de la amada, al definirla como una "belleza que vive / de matar siempre", esto es, como una mujer hermosa, pero cuyo trabajo y medio de subsistencia consiste en provocar orgasmos en sus clientes. Al menos, la singular cadencia que el compositor emplea al final del estribillo sugiere que dichos versos esconden un significado oculto e imposible de expresar literalmente, menos aún en un poema cortesano.

Así, y aunque por ahora se trate de una conjetura, tiene sentido pensar en el secretario personal del rey describiendo las desventuras sexuales y amorosas de este último por medio de una obra poética -y musical- de gran valor. Pero, dado lo escandalosas que aquellas hubieran resultado de haberse hecho públicas, lo haría por medio de claves que solo ellos dos y unos pocos más -entre los cuales se hallaba el compositor- podían comprender cabalmente ${ }^{103}$. En este caso, sin embargo, el escucha competente (o "escucha modelo", como le llama López Cano) ${ }^{104}$ al que nos hemos referido en el apartado previo abarcaría no un sector amplio de la sociedad española, sino un grupo reducido y exclusivo de personas. Las demás entenderían la obra y el texto en su sentido primario, lo que no les impediría disfrutar de su atractivo musical y literario.

Para concluir, quisiera recordar a Simon Frith, cuando señala que una de las funciones sociales de la música popular consiste en "proporcionarnos una vía para administrar la relación entre nuestra vida emocional pública y la privada", por su capacidad para dar "forma y voz" a emociones que "de otra manera no podrían expresarse sin resultar incómodas o incoherentes" $" 105$. Estoy plenamente de acuerdo con él, con la salvedad de que quitaría el adjetivo "popular" a su afirmación. La música -y las artes en general- poseen la capacidad de expresar aquello que, por cualquier razón, no podemos o no queremos decir por medio del lenguaje convencional. Así es hoy, y así era en la España del siglo XVII.

${ }^{101}$ J. A. Maravall: La cultura del Barroco..., p. 487.

${ }^{102}$ Ibid., pp. 261, 485-487.

${ }^{103}$ Vale la pena recordar que Felipe IV parece haber tenido conocimientos suficientes como para comprender los procedimientos poéticos y musicales que aquí hemos analizado. Jesús Cañas Murillo: "Corte y academias literarias en la España de Felipe IV", Anuario de Estudios Filológicos, 35, 2012, pp. 5-26; M. A. Flórez: Música teatral..., pp. 407-408.

${ }^{104}$ Véase la nota al pie 37.

${ }^{105}$ Simon Frith: "Hacia una estética de la música popular", Las culturas musicales: lecturas de etnomusicología, Francisco Cruces (ed.), Madrid, Trotta, 2001, pp. 423-424. 


\section{Apéndice}

Transcripción de Heridas de un rendido de compositor anónimo y letra de Antonio Hurtado de Mendoza, Libro de tonos humanos, ff. 8v-9 Biblioteca Nacional de España, M 1262

\section{Heridas en un rendido}

Libro de tonos humanos, ff. 8v-9

Biblioteca Nacional de España, M 1262
Compositor: desconocido Poeta: Antonio Hurtado de Mendoza Transcripción: Alejandro Vera

[Romance]
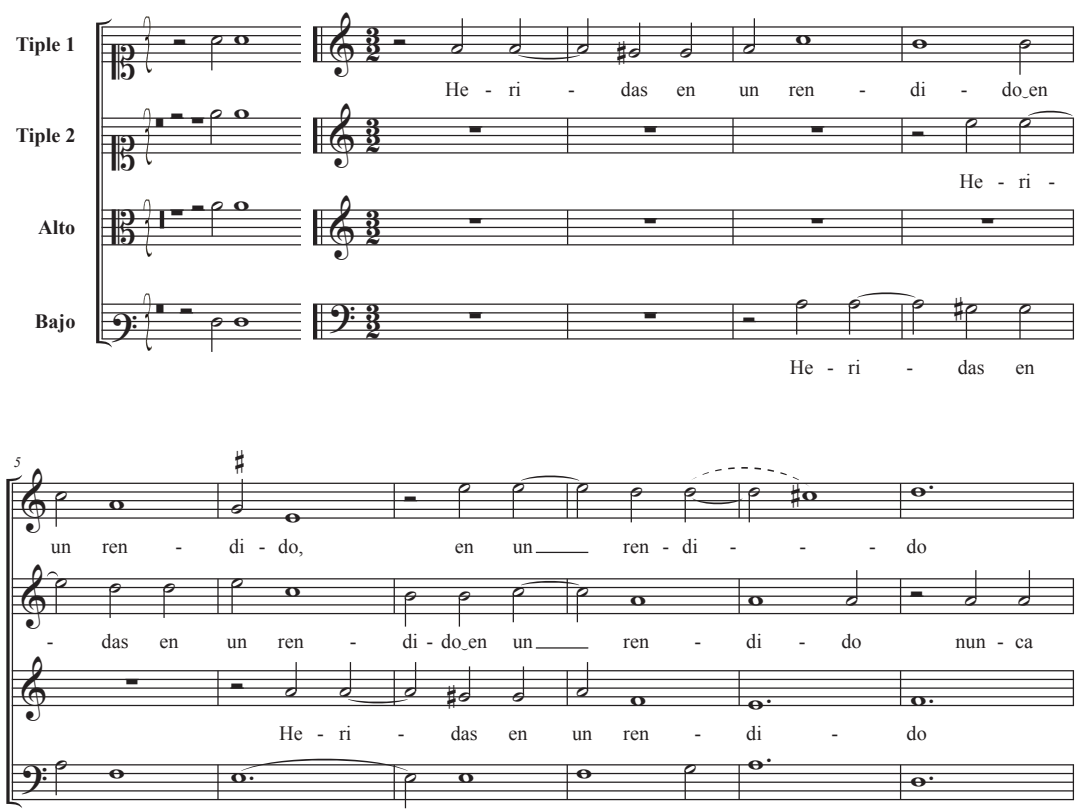

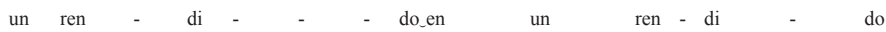

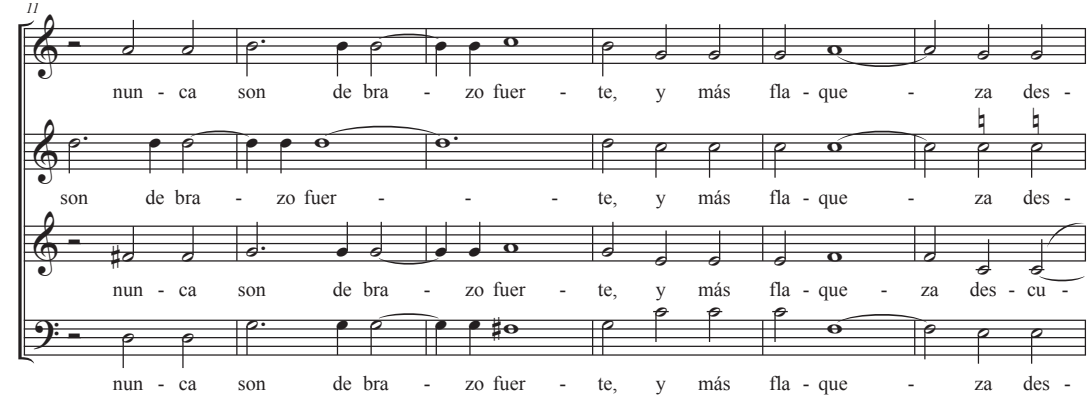




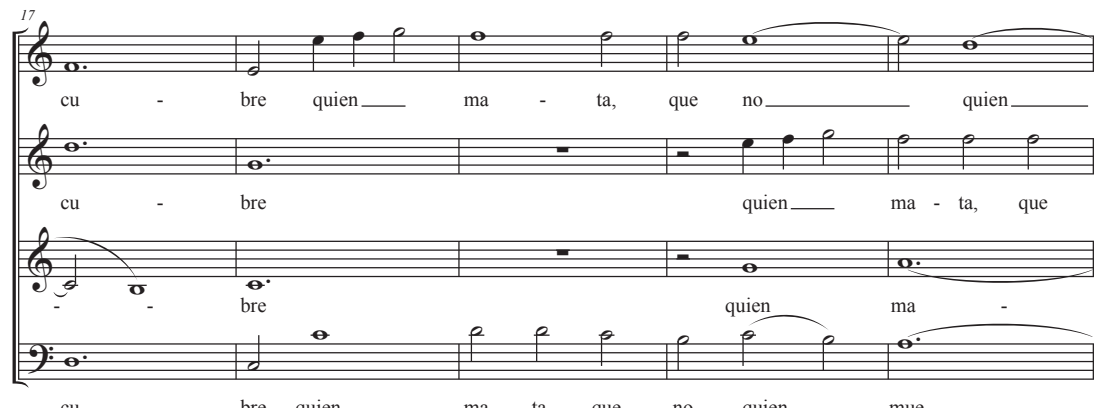
$\mathrm{cu} \quad-\quad$ bre quien
ma - ta, que
quien__ mue
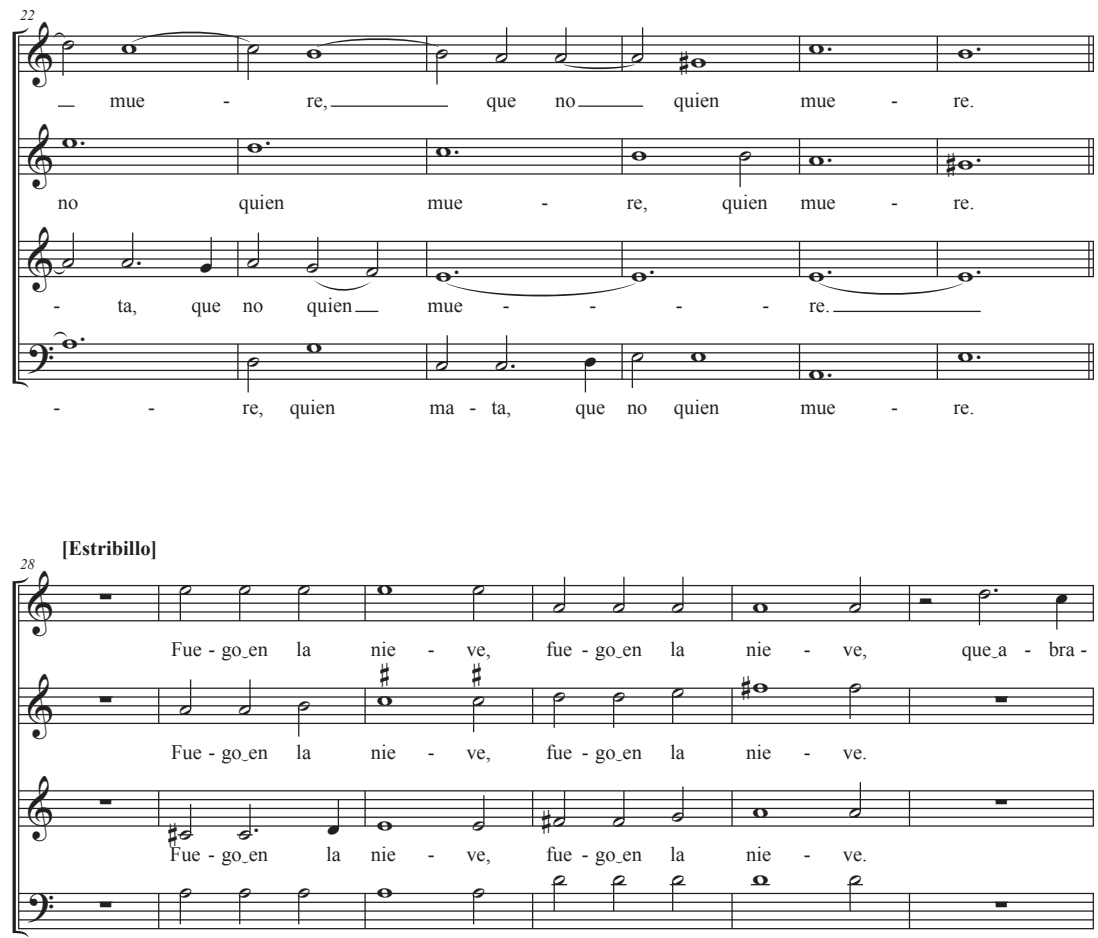

Fue-go_en la nie - ve, fue - go_en la nie - ve. 

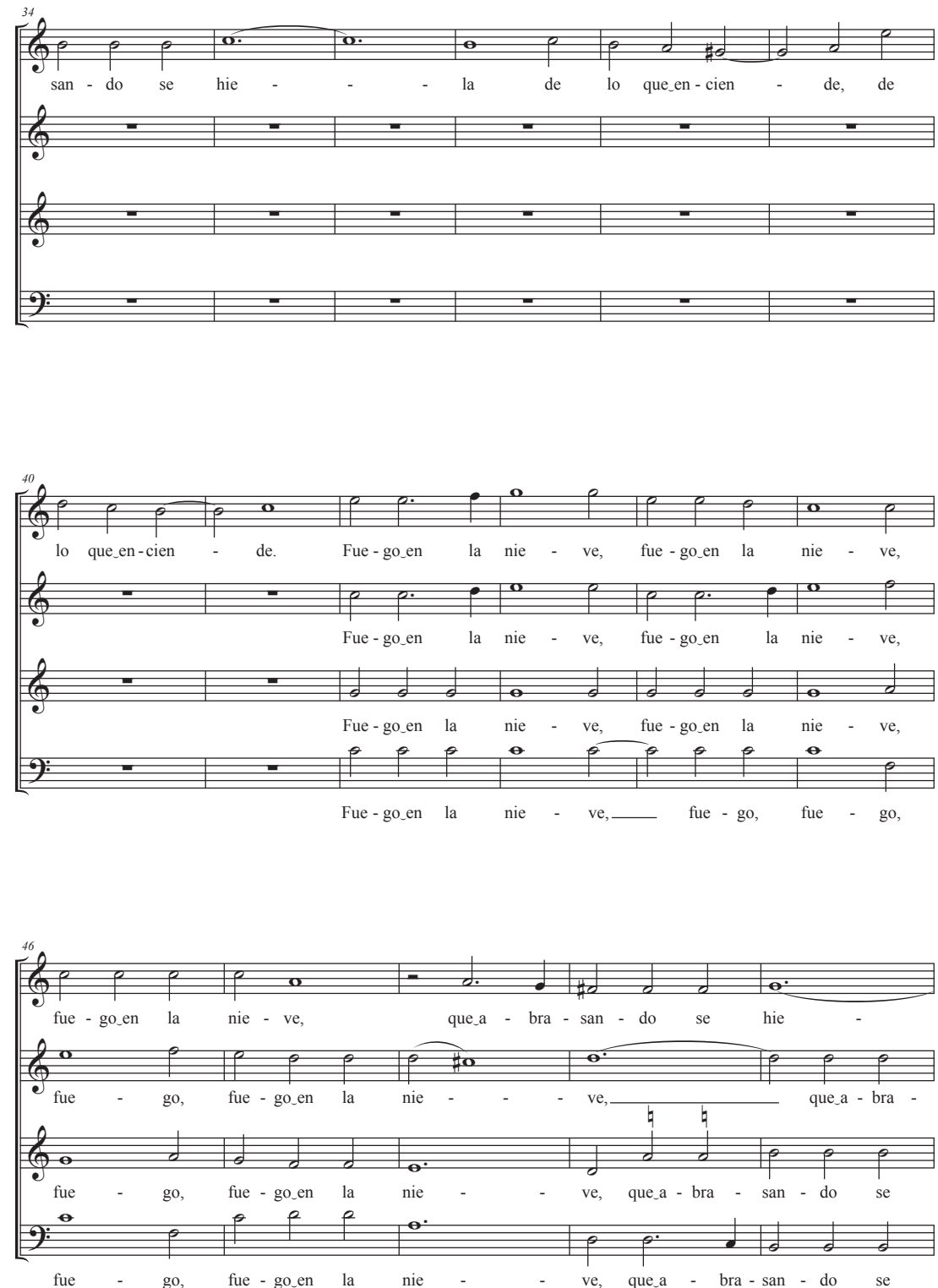

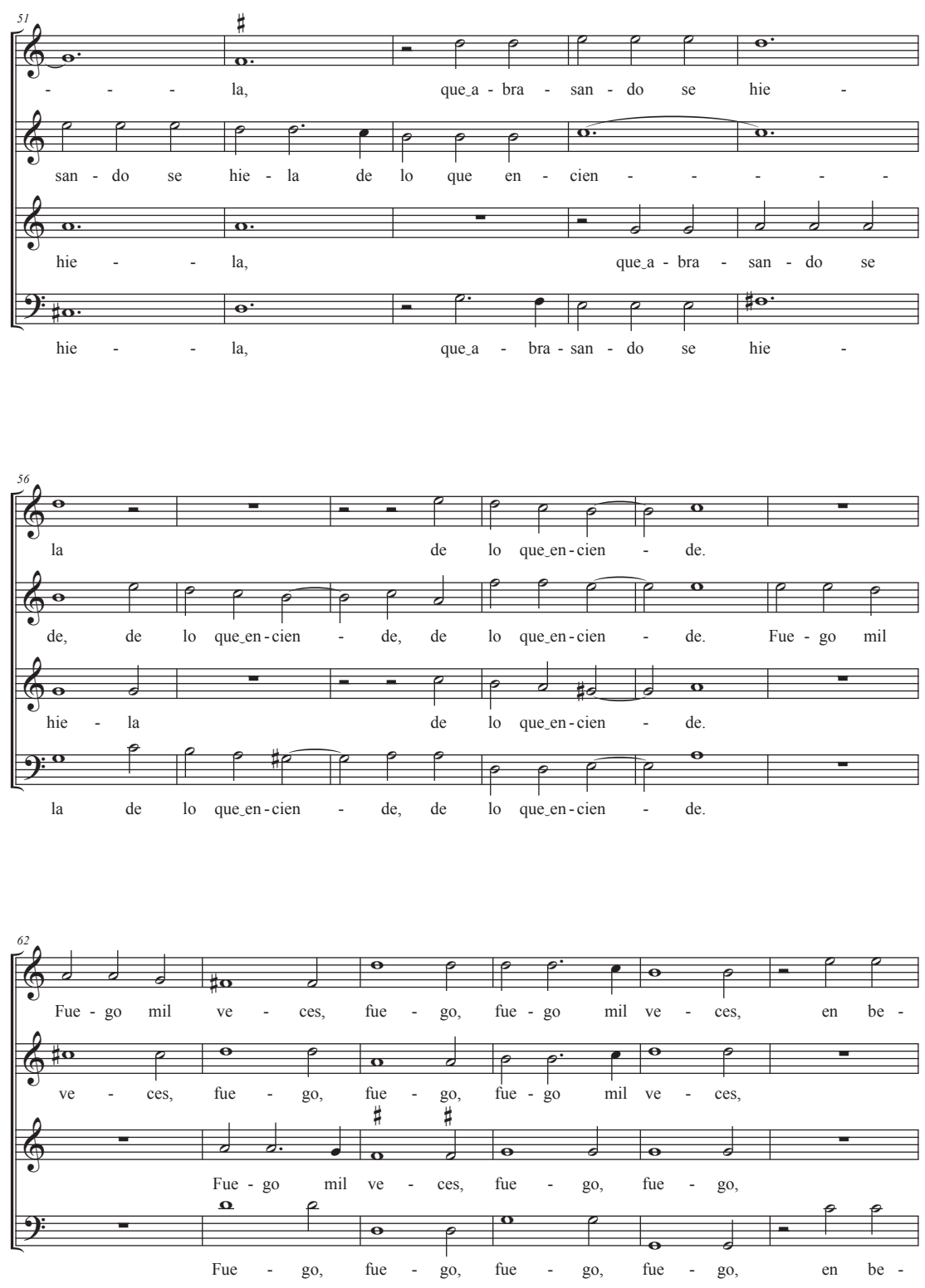


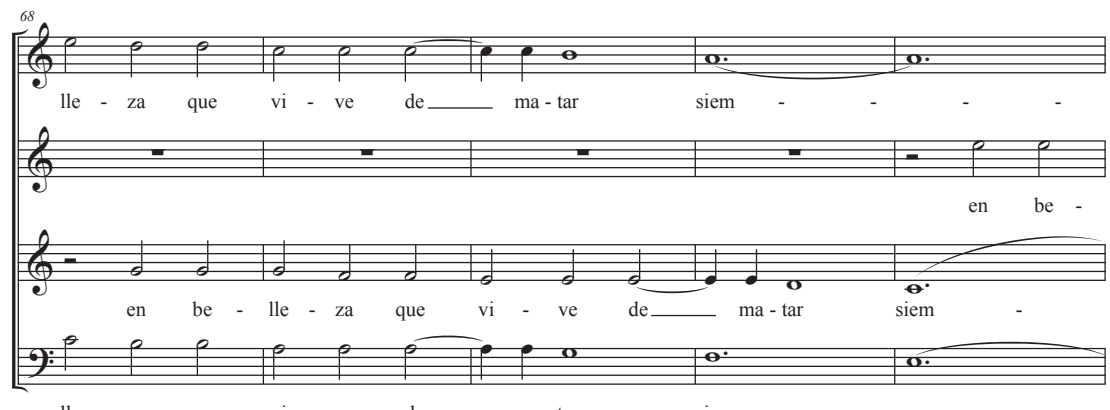

lle - za que vi - ve de_ ma-tar siem
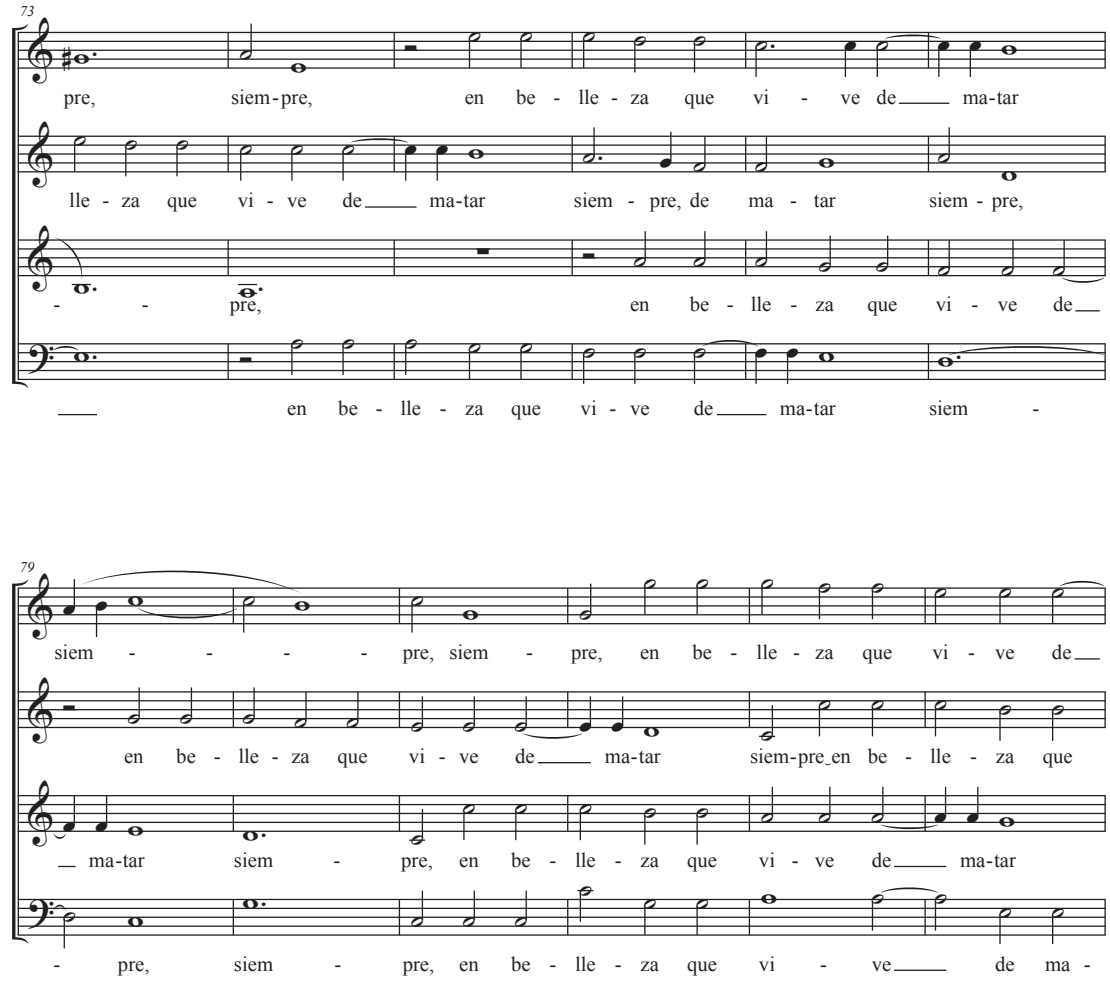


\section{Alejandro Vera Aguilera}
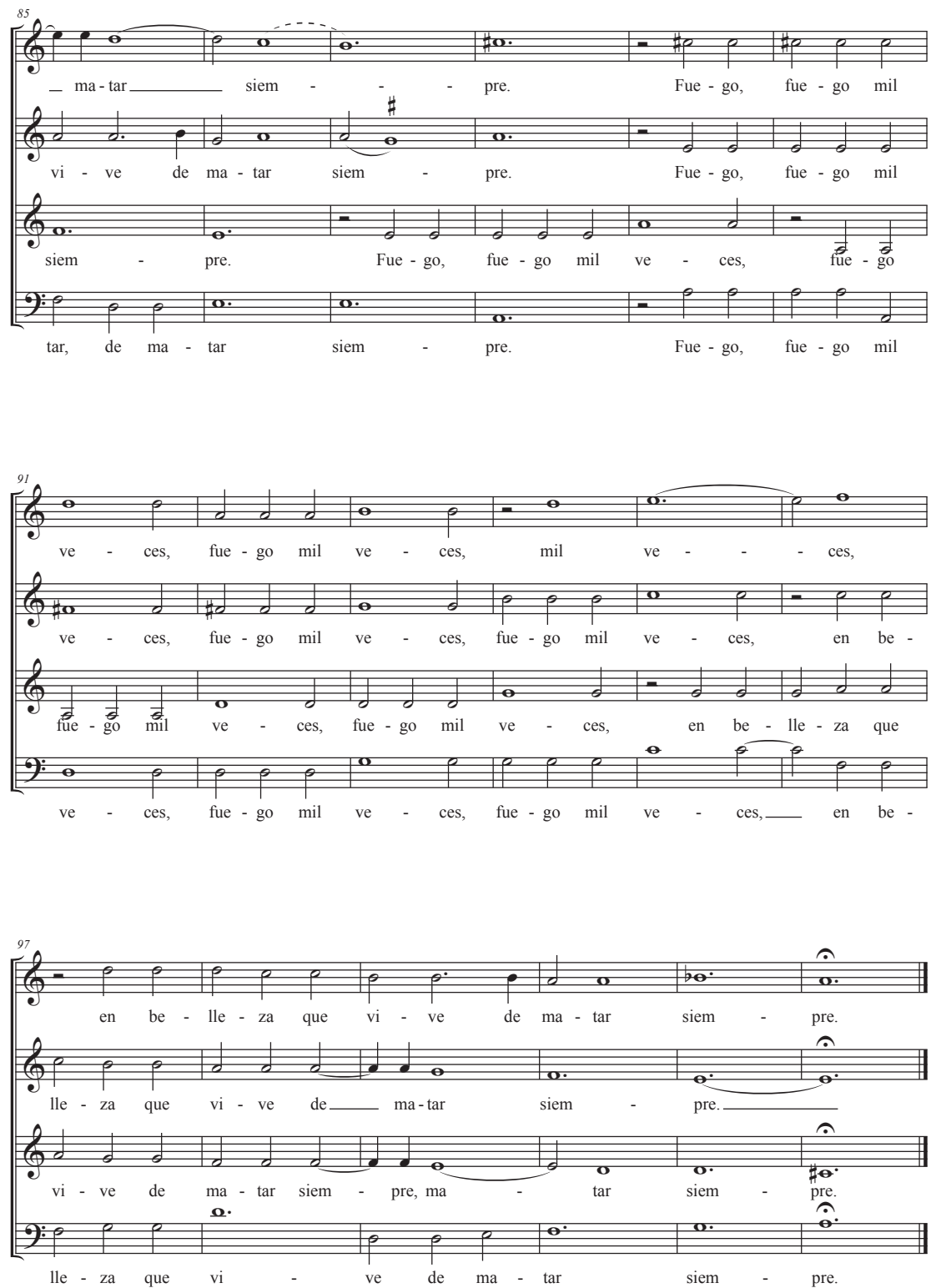


\section{Bibliografia}

Alonso Cortés, Narciso: "Pliegos de villancicos", Revista Bibliográfica, 4, 3, 1943 (separata).

Arriaga, Gerardo (ed.): José Marín (ca. 1619-1699):Tonos y villancicos, Madrid, ICCMU, 2008.

Beristáin, Helena: Diccionario de retórica y poética, México D. F., Editorial Porrúa, 1995.

Blanco, Mercedes: “El mecanismo de la ocultación. Análisis de un ejemplo de agudeza”, Criticón, 43, 1988, pp. 13-36.

Cantizano Pérez, Félix: "De las ninfas del Olimpo a las ninfas de las tasqueras: una visión de la prostitución en la España del Siglo de Oro”, eHumanista, 15, 2010, pp. 154-175.

Cañas Murillo, Jesús: "Corte y academias literarias en la España de Felipe IV”, Anuario de Estudios Filológicos, 35, 2012, pp. 5-26.

D’Assunção Barros, José: El campo de la historia: especialidades y abordajes, Santiago de Chile, Universidad Católica Silva Henríquez, 2008.

Davies, Gareth A.: "Antonio Hurtado de Mendoza: Biographical Notes”, Bulletin of Hispanic Studies, 34, 2, 1957, pp. 79-88.

Etzion, Judith: "The Spanish Polyphonic Cancioneros, c. 1580-c. 1650: A Survey of Literary Content and Textual Concordances", Revista de Musicología, 11, 1, 1988, pp. 65-107.

- (ed.): El Cancionero de la Sablonara, Londres, Tamesis Books, 1996.

Ezquerro, Antonio: La música vocal en Aragón en el segundo tercio del siglo XVII, tesis doctoral, edición en microficha, Bellaterra, Publicacions de la Universitat Autónoma de Barcelona, 1998.

Flórez, María Asunción: Música teatral en el Madrid de los Austrias durante el Siglo de Oro, Madrid, ICCMU, 2006.

Frith, Simon: "Hacia una estética de la música popular", Las culturas musicales: lecturas de etnomusicología, Francisco Cruces (ed.), Madrid, Trotta, 2001, pp. 413-435.

García Gallardo, Cristóbal L.:"La imagen de Andalucía en la teoría de la música: la cadencia andaluza", Andalucía en la música. Expresión de comunidad, construcción de identidad, Francisco José García Gallardo, Herminia Arredondo Pérez (coords.), Sevilla, Junta de Andalucía, 2014, pp. 107-121.

GinzBurG, Carlo: "Indicios. Raíces de un paradigma de inferencias indiciales”, Mitos, emblemas e indicios, Barcelona, Gedisa, 1994, pp. 138-175.

GonZÁLEZ Marín, Luis Antonio: "Recuperación o restauración del teatro musical español del siglo XVII”, La ópera en España e Hispanoamérica, Emilio Casares, Álvaro Torrente (eds.), Madrid, ICCMU, 2001, vol. 1, pp. 59-78.

GonzÁlez Valle, JoséVicente: "Relación música / texto en la composición musical en castellano del s. XVII. Nueva estructura rítmica de la música española”, Anuario Musical, 47, 1992, pp. 103-132.

-: "Relación entre el verso castellano y la técnica de composición musical en los villancicos de Fr. Manuel Correa (s. XVII)", Anuario Musical, 51, 1996, pp. 39-69.

HathawAy, Janet: "Laughter and Scandal: An Inquisition Censure in Late Hapsburg Madrid", Acta Musicologica, 75, 2, 2003, pp. 243-268.

-: Cloister, Court and City: Musical Activity of the Monasterio de las Descalzas Reales (Madrid), ca. 1620-1700, tesis doctoral, New York University, 2005. 
IgLeSIAs, Rafael: "Una posible nueva interpretación de los poemas de Quevedo de principios del reinado de Felipe IV relativos a fiestas de toros y de cañas", Journal of the Society for Renaissance and Baroque Hispanic Poetry, 10, 2, 2004, pp. 73-93.

Illari, Bernardo: Polychoral Culture: Cathedral Music in La Plata (Bolivia), 1680-1730, tesis doctoral, The University of Chicago, 2001.

Jorquera, Juan: Presencia de la música en la Compañía de Jesús de Madrid durante la primera mitad del siglo XVII, tesis doctoral, Universidad Autónoma de Madrid, 2016.

Josa, Lola; Lambea, Mariano: "Las 'trazas’ poético-musicales en el romancero lírico español”, Edad de Oro, 22, 2003, p. 61.

LAMBEA, Mariano; JosA, Lola (eds.): Libro de tonos humanos (1655-1656). Volumen I, Barcelona, CSIC, 2000.

—: Libro de tonos humanos (1655-1656). Volumen II, Madrid-Barcelona, CSIC, 2003.

—: Libro de tonos humanos (1655-1656). Volumen III, Madrid, CSIC, 2005.

—: Libro de tonos humanos (1655-1656). Volumen IV, Madrid, CSIC, 2010.

LóPEZ CANO, Rubén: De la retórica a la ciencia cognitiva. Un estudio intersemiótico de los tonos humanos de José Marín (ca. 1618-1699), tesis doctoral, Universidad de Valladolid, 2004.

—: Música y retórica en el Barroco, Barcelona, Amalgama Edicions, 2012.

MacPherson, Ian: "Secret Language in the Cancioneros: Some Courtly Codes", Bulletin of Hispanic Studies, 62, 1985, pp. 51-63.

Maravall, José Antonio: La cultura del Barroco. Análisis de una estructura histórica, Barcelona, Ariel, 1975.

Mattza, Carmela V.: "Écfrasis y mitología en La vida es sueño: el mito de Céfiro y Cloris", Anuario Calderoniano, 8, 2015, pp. 311-334.

Morros, Bienvenido: “Concepto y simbolismo en la poesía del Cancionero General', Revista de Literatura Medieval, 12, 2001, pp. 193-246.

Olmos, Ángel Manuel; Morales, Luisa: “Un nuevo y breve método de órgano y monacordio del siglo XVII en un libro de poemas de Antonio Hurtado de Mendoza”, Cinco siglos de música de tecla española: actas de los Symposia FIMTE 2002-2004, Luisa Morales (ed.), Almería, Asociación Cultural Leal, 2007,pp. 207-218.

Paz y Meliá,Antonio (ed.): Avisos de D. Jerónimo de Barrionuevo (1654-1658) y apéndice anónimo (1660-1664). Tomo IV, Madrid, Imprenta y Fundición de M.Tello, 1893.

PedRell, Felipe: Teatro lírico español anterior al siglo XIX, La Coruña, Canuto Berea y Compañía, 1897, vol. 3.

Pelinski, Ramón: Die Weltliche Vokalmusik Spaniens am Anfang des 17. Jahrhunderts, Tutzing, Hans Schneider, 1971.

Querol, Miguel:“El romance polifónico en el siglo XVII”, Anuario Musical, 10, 1955, pp. 111120.

Rice, Robin Ann: “'Oigan un silogismo señores’: erudición y burla en los villancicos de Sor Juana para celebrar San Pedro Apóstol en 1677”, Barroco de ambos mundos. Miradas desde Puebla, Ignacio Arellano, Robin Ann Rice (eds.), Nueva York, IDEA, 2019, pp. 263-284.

RoBledo, Luis: Juan Blas de Castro (ca. 1561-1631). Vida y obra musical, Zaragoza, Institución Fernando el Católico, 1989. 
Russell, Craig H.: Santiago de Murcia: Spanish Theorist and Guitarist of the Early Eighteenth Century, tesis doctoral, University of North Carolina at Chapel Hill, 1981.

SteIn, Louise K.: Songs of Mortals, Dialogues of the Gods. Music and Theater in Seventeenth-Century Spain, Oxford, Clarendon Press, 1993.

-: "Eros, Erato, Terpsíchore and the Hearing of Music in Early Modern Spain", The Musical Quarterly, 82,3/4, 1998, pp. 654-677.

Torrente, Álvaro: "Música de plata en un siglo de oro”, Historia de la música en España e Hispanoamérica. 3. La música en el siglo XVII, Álvaro Torrente (ed.), Madrid, Fondo de Cultura Económica de España, 2016, pp. 29-83.

—: "Tonos, bailes y guitarras: la música en los ámbitos privados”, Historia de la música en España e Hispanoamérica. 3. La música en el siglo XVII, Álvaro Torrente (ed.), Madrid, Fondo de Cultura Económica de España, 2016, pp. 189-268.

-: "El villancico religioso", Historia de la música en España e Hispanoamérica. 3. La música en el siglo XVII, Álvaro Torrente (ed.), Madrid, Fondo de Cultura Económica de España, 2016, pp. $433-530$.

Torrente Ballester, Gonzalo: Crónica del rey pasmado, Barcelona, Planeta, 1989.

Treitler, Leo: Music and the Historical Imagination, Cambridge / Massachusetts / Londres, Harvard University Press, 1989.

VAldivia, Francisco Alfonso: Guitarra, sistemas de notación y cultura popular. Los sistemas de notación abreviada de acordes y la popularización de la guitarra en España durante el siglo XVII, tesis doctoral, Universidad de Málaga, 2011.

Valenzuela, Salvador: Armonía modal, modo de Mi y flamenco. Aproximación al 'Modo de Mi armónico' como sistema musical de tradición hispana, tesis doctoral, Universidad de Granada, 2016.

Vera, Alejandro: Música vocal profana en el Madrid de Felipe IV: el "Libro de tonos humanos" (1656), Lleida, Institut d'Estudis Ilerdencs, 2002.

Recibido: 2-6-2020

Aceptado: 23-12-2020 